\title{
African Rainfall Climatology Version 2 for Famine Early Warning Systems
}

\author{
NiCHOLAS S. NOVELLA \\ NOAA/National Centers for Environmental Prediction/Climate Prediction Center, Camp Springs, Maryland, \\ and Wyle Information Systems, McLean, Virginia \\ WASSILA M. THIAW \\ NOAA/National Centers for Environmental Prediction/Climate Prediction Center, Camp Springs, Maryland
}

(Manuscript received 22 November 2011, in final form 8 August 2012)

\begin{abstract}
This paper describes a new gridded, daily 29-yr precipitation estimation dataset centered over Africa at $0.1^{\circ}$ spatial resolution. Called the African Rainfall Climatology, version 2 (ARC2), it is a revision of the first version of the ARC. Consistent with the operational Rainfall Estimation, version 2, algorithm (RFE2), ARC2 uses inputs from two sources: 1) 3-hourly geostationary infrared (IR) data centered over Africa from the European Organisation for the Exploitation of Meteorological Satellites (EUMETSAT) and 2) qualitycontrolled Global Telecommunication System (GTS) gauge observations reporting 24-h rainfall accumulations over Africa. The main difference with ARC1 resides in the recalibration of all Meteosat First Generation (MFG) IR data (1983-2005). Results show that ARC2 is a major improvement over ARC1. It is consistent with other long-term datasets, such as the Global Precipitation Climatology Project (GPCP) and Climate Prediction Center (CPC) Merged Analysis of Precipitation (CMAP), with correlation coefficients of 0.86 over a 27-yr period. However, a marginal summer dry bias that occurs over West and East Africa is examined. Daily validation with independent gauge data shows RMSEs of 11.3, 13.4, and 14, respectively, for ARC2, Tropical Rainfall Measuring Mission Multisatellite Precipitation Analysis 3B42, version 6 (3B42v6), and the CPC morphing technique (CMORPH) for the West African summer season. The ARC2 RMSE is slightly higher for Ethiopia than those of CMORPH and 3B42v6. Both daily and monthly validations suggested that ARC2 underestimations may be attributed to the unavailability of daily GTS gauge reports in real time, and deficiencies in the satellite estimate associated with precipitation processes over coastal and orographic areas. However, ARC2 is expected to provide users with real-time monitoring of the daily evolution of precipitation, which is instrumental in improved decision making in famine early warning systems.
\end{abstract}

\section{Introduction}

Since the advent of remote sensing, many satellite rainfall estimate datasets have been developed to generate a more comprehensive level of global rainfall coverage. Often, the algorithms used consist of combining data from in situ rain gauge networks, and remote sensing satellite data from both geostationary and polarorbiting platforms such as the Tropical Rainfall Measuring Mission (TRMM; Huffman et al. 2007), the Global Precipitation Climatology Project (GPCP; Huffman et al. 1997), and the Climate Prediction Center (CPC) Merged

Corresponding author address: Nicholas Novella, NOAA/Climate Prediction Center, Development World Weather Bldg., 5200 Auth Rd., Camp Springs, MD 20746.

E-mail: nicholas.novella@noaa.gov
Analysis of Precipitation (CMAP; Xie and Arkin 1997). In 1998, the CPC developed the Rainfall Estimator (RFE; Herman et al. 1997) in response to the need for higher-resolution operational daily rainfall estimates to support the humanitarian aid programs of the U.S. Agency for International Development (USAID)/ Famine Early Warning Systems Network (FEWS-NET). The RFE has continued to provide an accurate monitoring of large-scale and regional climatic and hydrometeorological trends. It is a unique product relative to other satellite rainfall estimators because of its high, $0.1^{\circ}$ gridded spatial resolution, and its ability to blend gauge and satellite information on a near-real-time basis to provide daily (0600-0600 UTC) rainfall estimates over the African continent. In 2001, CPC implemented an advanced RFE algorithm (version 2.0, hereinafter referred to as RFE2) based on the methods of Xie and Arkin (1996). 
The RFE2 exhibited improvement over its predecessor by reducing bias, and increasing both estimation accuracy and computational efficiency (Love et al. 2004). The input data for the RFE2 comes from four operational sources: 1) daily Global Telecommunications System (GTS) rain gauge data, 2) the Geostationary Operational Environmental Satellite (GOES) precipitation index (GPI) calculated from cloud-top infrared (IR) temperatures on a half-hourly basis (Arkin and Meisner 1987), 3) Special Sensor Microwave Imager (SSM/I)-based estimates (Ferraro and Marks 1995; Ferraro et al. 1996), and 4) Advanced Microwave Sounding Unit (AMSU)-based rainfall estimates (Zhao et al. 2000).

Although the RFE2 product has served as the principal rainfall estimator for USAID/FEWS-NET operations, the brevity of the dataset record (2001-present) does not allow users to derive meaningful rainfall anomalies to assess the current state and evolution of the climate over Africa. Consequently, the original Africa Rainfall Climatology (ARC1) was developed based on the same algorithm employed in the RFE2 algorithm (Xie and Arkin 1996). The usefulness of ARC has been in its ability to provide daily snapshots of precipitation anomalies over various time scales (e.g., weekly, monthly, seasonal, etc.), which helps to facilitate operational climate monitoring at CPC, a process by which we identify and regularly analyze anomalous precipitation trends on a near-real-time basis. This process is critical to decision making in agriculture, water resources, and food security over Africa. Of the four main inputs used in the RFE2, the ARC1 incorporated only gauge and IR data because of their availability and consistency over time. A historical reprocessing of gauge and IR data from 1995 to 2005 was performed by Love et al. (2004), which resulted in a daily, high-resolution precipitation estimate dataset from 1995 to the present. However, due to inconsistencies in the original reprocessing that led to a large bias in the original ARC1 data, this dataset no longer responds to current needs for operational climate monitoring. Furthermore, a higher number of years was needed to make the ARC1 climatological record more stable. This has prompted us to utilize a new, long-term precipitation dataset for operational monitoring and climate analysis.

The recent acquisition of historical, recalibrated IR imagery and daily summary gauge data has enabled our reconstruction of the ARC climatology dataset from 1983 to the present. A new, reconstructed Africa Rainfall Climatology (ARC2) offers a number of advantages relative to other long-term climatological rainfall datasets that are widely used. First, high-resolution historical rainfall estimates on a real-time, daily basis would help not only to monitor precipitation associated with synoptic and mesoscale disturbances, but also to undertake studies of extreme events, wet and dry spells, the number of rain days (i.e., rainfall frequency), and the onset of the rainfall seasons. This will further enhance our understanding of the mechanisms associated with climate variability on shorter time scales. Second, a $0.1^{\circ}(\sim 10 \mathrm{~km})$ spatial resolution allows users to see rainfall phenomena on local scales that cannot be captured by coarser climate datasets. For the FEWS-NET program, this local-scale resolution has also been instrumental in assessing the impacts of rainfall on agriculture and water resource management. Third, the ARC2 maintains the same two inputs that remain continuous and homogeneous over time. This historical consistency is attributed to a single algorithm, requiring the use of calibrated IR satellite imagery with quality-controlled gauge observations. This straightforward estimation approach differs from other satellite products where there are often asynchronous rainfall inputs throughout a long-term historical dataset record. Specifically, the utilization of two uniform inputs is expected to minimize the possibility of introducing bias associated with new satellite sensors. This homogeneity is also expected to elucidate long-term climatic trends in daily precipitation. Finally, because the same algorithm as the operational RFE2 is used, ARC2 precipitation estimates are also available in near-real time, allowing the dataset to be routinely updated on a daily basis. All of these features make the new ARC2 dataset unique.

The objective of this paper is to report on a new gridded, daily 28-yr precipitation climatology dataset centered over Africa. This climatology was developed from the daily reprocessing of quality-controlled historical IR and gauge data using the operational RFE2 algorithm. Section 2 describes the input data and their respective sources that were selected for the new ARC2. Section 3 reports on the calibration of historical IR imagery as well as the two-step merging methodology as described by (Xie and Arkin 1996). Section 4 shows the results of the completed ARC2, and compares the ARC2 with the original ARC1, as well as other long-term gauge- and satellite-derived climatological precipitation datasets over a 27-yr period (19832009). Independent gauge data in the Gulf of Guinea region of Africa are also presented in a validation between the ARC2 and the other long-term precipitation datasets from 1997 to 2004, followed by a discussion on how the $\mathrm{ARC} 2$ is used in operational climate monitoring for Africa at CPC. Section 5 provides a summary of our analysis results and final remarks of the new ARC2 dataset.

\section{Inputs}

The operational daily precipitation estimate method (RFE2) incorporates gauge data, geostationary IR data, and polar-orbiting microwave SSM/I and AMSU-B 
satellite data. The primary differences between the RFE2 and ARC1-ARC2 products are 1) the ARC method uses a subset of the inputs used in the RFE2, that is, only gauge data and GPI estimates derived from geostationary IR are ingested, and 2) the GPI estimates use a 3-hourly temporal sampling of IR temperatures as opposed to the half-hourly sampling used in the RFE2. While passive microwave information has proven very useful in other satellite rainfall estimation products, continuous daily records do not exist as long as for the IR imagery. Specifically, the earliest available SSM/I and AMSU-B rainfall retrieval records extend back to 1987 and 1998, respectively, and despite their improvements during the last several years, they are still undergoing quality control and calibration checks to ensure better estimate accuracy and homogeneity (Semunegus et al. 2010; Vila et al. 2007). A key goal in developing the ARC2 was to maintain the ingestion of daily data that exhibit the least amount of heterogeneity, whose input lengths also remain concurrent over a longterm historical record. Both gauge and geostationary IR data possess a higher level of availability, as well as better spatial coverage and reliability than passive microwave data from 1983 to the present. This feature was considered most desirable in constructing a stable and consistent rainfall climatology dataset, despite any potential loss in estimation accuracy. In a cross-validation exercise between the RFE2 and ARC methods, Love et al. (2004) found that both the gauge and IR inputs, exclusively, maintained a relatively high correlation and low bias with station gauge observations. However, it is noted that the exclusion of microwave rainfall retrievals tends to lead to a failure in capturing locally heavy precipitation events (Love et al. 2004). Table 1 lists correlation coefficients between in situ observations and rainfall estimates using a variety of input combinations. While a slightly lower correlation was obtained using gauge and IR data than all four inputs, these results were encouraging due to the smallest amount of bias yielded over all combinations. A preliminary reprocessing of historical IR data from 1983 to 1989 also suggested that reducing the daily IR sampling from half-hourly to 3-hourly intervals in calculating the GPI estimates led to no significant differences in the final rainfall estimates. Thus, for computer efficiency, we acquired 8 threehourly IR images instead of the 48 half-hourly IR images that were available.

The first input source used to develop the ARC2 was 24-h in situ accumulated rainfall observations recorded from the GTS gauge network. GTS data over Africa consist of a global array of stations reporting 24-h (06000600 UTC) summaries of meteorological observations such as temperature maximums and minimums, winds,
TABLE 1. Monthly accumulated rainfall as estimated from the RFE2 algorithm, compared with station gauge observations in the Sahel during December 1999 (Love et al. 2004).

\begin{tabular}{lcc}
\hline \multicolumn{1}{c}{ Data } & ${\text { Bias }\left(\mathrm{mm} \mathrm{day}^{-1}\right)}$ & Correlation \\
\hline GPI only & 2.26 & 0.35 \\
SSM/I only & -0.24 & 0.32 \\
AMSU only & -0.15 & 0.09 \\
GPI + SSM/I + AMSU + GTS & -0.15 & 0.50 \\
$\quad$ (RFE inputs) & & \\
GPI + GTS (ARC inputs) & -0.04 & 0.48 \\
\hline
\end{tabular}

precipitation, etc. For the ARC2, we combined the existing GTS gauge database at CPC with historical daily GTS data extending back to 1983. The historical GTS data from 1983 to 1994 were acquired from the archives at the University Corporation for Atmospheric Research (UCAR) in daily summary file format. These daily summary files were reformatted to match the currently assimilated GTS format ingested by the RFE2 algorithm in order to build a daily GTS gauge record from 1983 to the present. Out of an approximate 7500 GTS gauges that exist globally, less than 1200 stations typically report in Africa on a daily basis. This accounts for about a $1: 23000 \mathrm{~km}^{2}$ gauge-to-area ratio across the African continent. Despite the paucity of GTS stations and their relatively poor distribution across Africa, these gauge data are still "ground truth" and remain instrumental in constructing a daily, historical precipitation record. And while the lack of gauge data over Africa is less beneficial when constructing historical precipitation estimates, the near-real-time availability of the GTS offers a desired timeliness when generating rainfall anomaly fields on an operational basis. Each day, GTS gauge observations are interpolated onto a $0.1^{\circ} \times 0.1^{\circ}$ grid over Africa using the methods of Shepard (1968).

The second input source is full-disk, Meteosat geostationary IR imagery centered at $0^{\circ}$ longitude using the 10.5-12.5- $\mu \mathrm{m}$-wavelength window channel. From 1983 to 2005, historical 3-hourly IR imagery for Meteosat First Generation Satellites 2-7 (MFG-2-7) was collected from the European Organisation for the Exploitation of Meteorological Satellites (EUMETSAT) via ftp transmission at CPC. From 2006 onward, precalibrated Meteosat Second Generation (MSG) IR data have been continuously forwarded to CPC for operations on a daily basis. The advancement of geostationary calibration methods associated with MSG data led to nonnegligible discrepancies between the MFG and MSG raw IR imagery. This warranted careful treatment of the calibration of MFG raw IR imagery to ensure uniformity with the total IR input record from 1983 to the present. The 
recalibrated MFG IR data from 1983 to 2005 are what mainly distinguishes the new ARC2 from the previous ARC1 dataset. The methodology used to calibrate MFG IR data from 1983 to 2005 , as well as the conversion to rainfall estimates (i.e., GPI), are discussed in the following section.

\section{Methodology}

The methodology used to develop ARC2 consisted of compiling $23 \mathrm{yr}$ of daily GTS gauge data and threehourly IR data from 1983 to 2005, similar to Love et al. (2004) in the initial reprocessing of the ARC1 dataset (1995-2005). In ARC2, however, much of the work was devoted to correctly calibrating all MFG IR data from 1983 to 2005, and then perform the daily reprocessing using the operational RFE2 algorithm for this period. From 2006 to present, the daily ARC1 rainfall data that were generated using precalibrated MSG IR data at CPC were simply appended to the end of ARC2 dataset. As a result, the ARC1 and ARC2 rainfall estimates are identical from 2006 to present. The details of the MFG calibration methods are explained in the IR calibration subsection, followed by a brief description of the RFE2 algorithm, which as discussed above is based on Xie and Arkin (1996).

\section{a. IR calibration and GPI}

Open Meteosat Transition Program (OpenMTP 1.5) files from EUMETSAT's satellite data archive were selected as the best available IR format to cover the main reconstruction period from 1983 to 2005. To preprocess the raw 3 -hourly IR data, calibration coefficient and space count values were first required to convert the raw digital data counts to brightness temperatures for all MFG satellites. The calibration relation is expressed as

$$
R=\mathrm{CC}\left(C_{\mathrm{nt}}-\mathrm{SC}\right),
$$

where $R$ equals the radiance and $\mathrm{CC}, C_{\mathrm{nt}}$, and SC correspond to the calibration coefficient, digital Meteosat counts, and space counts, respectively. An analytic relationship derived from Planck's law was applied to explain the relationship between radiance $R$ and brightness temperatures $T_{b}$ :

$$
T_{b}=B /(\ln R-A) .
$$

EUMETSAT provided semidaily CC and SC data on a separate online source (EUMETSAT 2011a). Radiance and brightness temperature reference tables for Meteosat2-7 individually were also provided (EUMETSAT 2010, personal communication). From these reference tables, however, a logarithmic fitting model was needed to fill in the gaps between radiance and the corresponding brightness temperature. Each model applied yielded the least amount of error based on the reference tables for each Meteosat satellite. A continuous array of corrected radiance and brightness temperature pairs allowed the derivation of constants $A$ and $B$ so that each radiance value had a calibrated brightness temperature. Once metadata were obtained, a georeferencing routine (EUMETSAT 2011b) was then implemented to synthesize 3-hourly brightness temperatures on a $0.1^{\circ} \times 0.1^{\circ}$ grid covering the African continent.

Once all MFG IR data were fully calibrated, the GPI algorithm was used to convert 3-hourly brightness temperature images to daily rainfall estimates. GPI rainfall is derived from the fractional coverage of cloudtop IR temperatures less than $235 \mathrm{~K}$ over a $24-\mathrm{h}$ period, which is then multiplied by an empirical rain-rate constant of $3.0 \mathrm{~mm} \mathrm{~h}^{-1}$ (Arkin and Meisner 1987). Because IR data are measured from geostationary satellite platforms, the greatest advantage of the GPI method is that it succeeds in capturing the large-scale spatial distribution of precipitation. While the GPI uses cloud-top temperatures as a proxy for determining rain rate, studies have shown that the GPI method yields good results in the tropics and warm-season extratropics (Arkin and Xie 1994; Xie and Arkin 1995; Joyce and Arkin 1997). This is particularly useful considering that deep convection is the primary driver for precipitation over Africa. However, these studies also identify the GPI's weakness in estimating rainfall over land areas during cold seasons, emphasizing the need to combine the GPI with in situ data to increase performance. These historical daily GPI estimates were computed from 0600 to 0600 UTC in order to be concurrent with the daily GTS gauge totals for merging.

\section{b. Two-step merging methodology}

The two-step merging process is the essence of the RFE2 and ARC2 products, as it is here that all inputs are blended and final rainfall estimates are produced. As outlined in Xie and Arkin (1996), the first step aims to reduce the random error associated with the satellite input data. For the RFE2, this is performed by linearly combining GPI, SSM/I, and AMSU-B data through a maximum likelihood method. Weighting coefficients for each satellite input source are calculated from their random errors, which are determined by comparing the estimated precipitation with the actual rain gauge values on a daily basis. These coefficients are inversely proportional to the random error of each satellite input, which grants greater leverage to accurate satellite estimates. However, the exclusion of passive microwave 
inputs (i.e., SSM/I and AMSU-B) leads to only one weighting coefficient for the GPI in the ARC2.

Because the first step contains bias from the original inputs, the second step is designated to remove the bias by blending the first-step output with the gauge data through the methodology of Reynolds (1988). Specifically, the bias-corrected satellite output was used to define the spatial distribution and extent of rainfall, while the gauge data were used to determine the magnitude of the precipitation fields. Values of gridded precipitation were calculated by solving a Poisson's equation, in which the forcing term and boundary conditions were determined from the first-step output and gauge data, respectively. By doing so, the final rainfall estimate for any particular grid point retains a station's reported value when in close proximity to that station, and greater reliance is placed upon the satellite estimate as distance increases from the station. For quality control purposes, some restrictions were applied following this two-step merging process: 1 ) satellite grid estimates that exceed a $300-\mathrm{mm}$ threshold are replaced by satelliteonly (nonmerged) estimates, 2) at least four 3-hourly IR images are required to compute the daily GPI satellite estimates, and 3) at least 200 GTS stations reporting over Africa are required to compute the daily rain gauge analysis. If either criterion 2 or 3 is not met, the algorithm will not process for any given day, resulting in missing data. These conditions were also applied in the historical reprocessing of the ARC2.

\section{Results and discussion}

The new, operational ARC2 dataset consists of daily, gridded $0.1^{\circ} \times 0.1^{\circ}$ rainfall estimates with a spatial domain of $40^{\circ} \mathrm{S}-40^{\circ} \mathrm{N}$ and $20^{\circ} \mathrm{W}-55^{\circ} \mathrm{E}$, encompassing the African continent from 1 January 1983 to the present and forward into the future. Figure 1a illustrates the spatial distribution of mean annual ARC2 rainfall on a $0.1^{\circ}$ grid over Africa from 1983 to 2010 . Mean precipitation maxima greater than $6 \mathrm{~mm} \mathrm{day}^{-1}$ are observed along the coastal Gulf of Guinea region, the central African Congo, and over areas surrounding Madagascar in the southwestern Indian Ocean basin. Mean precipitation minima of less than $1 \mathrm{~mm} \mathrm{day}^{-1}$ are seen across the subtropics, which encompasses the Sahara Desert in the Northern Hemisphere, St. Helena's high in the southern Atlantic Ocean, and the semiarid Kalahari region across continental southwestern Africa. Figure $1 \mathrm{~b}$ displays a time series of the ARC2 daily annual cycle. Climatologically, the annual rainfall maximum over Africa typically develops during March-May, when convection is extremely active within the intertropical convergence zone (ITCZ) in the Gulf of Guinea region, a.

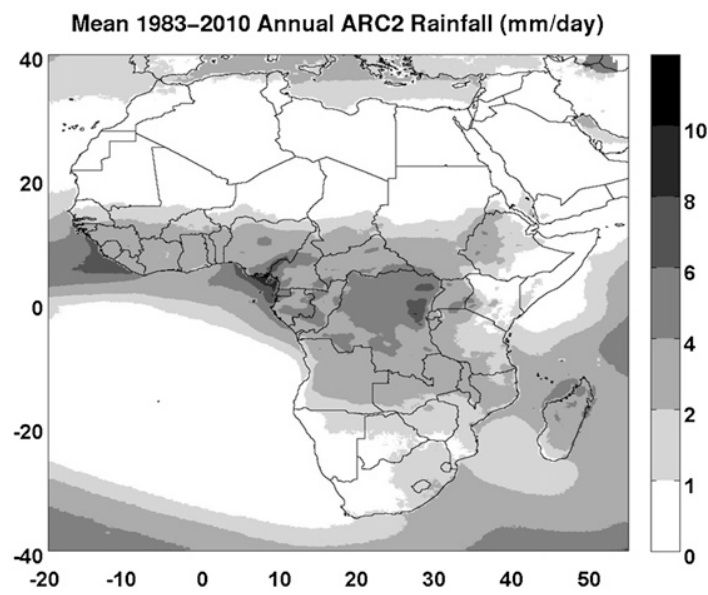

b.

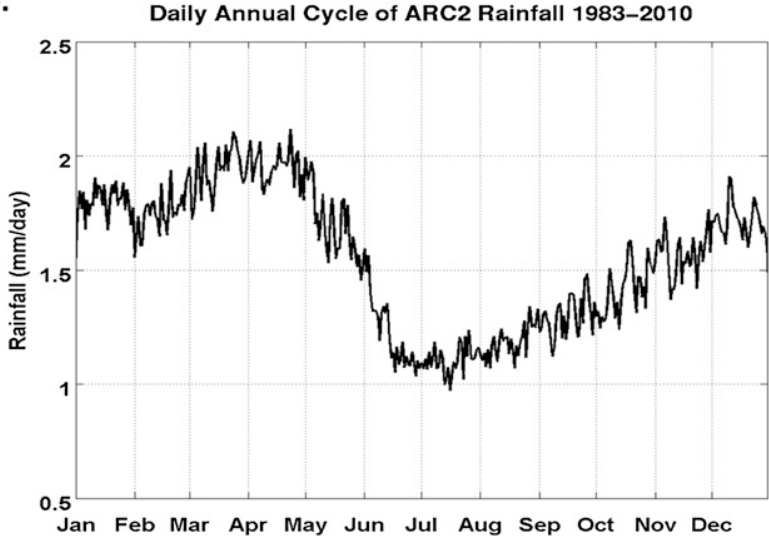

FIG. 1. (a) Spatial mean of annual ARC2 rainfall $\left(\mathrm{mm} \mathrm{day}^{-1}\right)$ at $0.1^{\circ}$ resolution over Africa from 1983 to 2010 and (b) daily annual cycle of ARC2 rainfall (mm day ${ }^{-1}$ ) over the African domain $\left(40^{\circ} \mathrm{S}-40^{\circ} \mathrm{N}\right.$ and $\left.20^{\circ} \mathrm{W}-55^{\circ} \mathrm{E}\right)$ from 1983 to 2010 .

the Congo rain forest region, and equatorial eastern Africa. This maximum is followed by the annual minimum during the months of May-October when rainfall shifts to the northern tropical belt region $\left(0^{\circ}-20^{\circ} \mathrm{N}\right)$ between the Sahara Desert and central Africa to coincide with the West African monsoon. After September, the gradual increase in annual mean precipitation is associated with the onset of the rains in central Africa, southern Africa, and equatorial eastern Africa. During this time, the distribution of rainfall is quite robust across much of the continental Southern Hemisphere and the southwestern Indian Ocean basin until approximately April.

\section{a. Intercomparison of long-term monthly products}

In the following, we compare $\mathrm{ARC} 2$ with $\mathrm{ARC} 1$, and with three historical long-term precipitation datasets including version 2.1 of the GPCP combined precipitation dataset (Huffman et al. 1997; Adler et al. 2003; Huffman and Bolvin 2009), CMAP (Xie and Arkin 1997), 
and the 50-yr monthly global analysis of gauge observations [NOAA Precipitation Reconstruction over Land (PREC/L); Chen et al. 2002]. The latter three datasets were chosen because of their historical record length, a much higher number of stations used in the gauge inputs [Community Atmosphere Model, Global Historical Climatology Network, and Global Precipitation Climatology Centre (GPCC)], and the fact they have been widely used in research. For example, over 2000 stations are used on average in the GPCC dataset (Rudolf et al. 1994) over the African continent, although there is a significant reduction in this number over the last $10 \mathrm{yr}$. With the exception of ARC1 covering 1995-present, all comparative analyses consisted of monthly precipitation means covering $40^{\circ} \mathrm{S}-40^{\circ} \mathrm{N}$ and $20^{\circ} \mathrm{W}-55^{\circ} \mathrm{E}$ from 1983 to 2009 . Daily ARC1 and ARC2 data were averaged into monthly values due to the unavailability of the long-term datasets on a daily time scale. Comparisons with the PREC/L gauge-based analysis used an ocean mask to assess landonly precipitation across the African continent.

A long-term time series depicting areal-averaged mean yearly rainfall, as well as a monthly annual cycle of precipitation for the domain spanning $40^{\circ} \mathrm{S}-40^{\circ} \mathrm{N}$ and $20^{\circ} \mathrm{W}-55^{\circ} \mathrm{E}$ between the ARC2, ARC1, GPCP, and CMAP products are illustrated in Figs. 2a,b. First, in comparing the new ARC2 with the original ARC1, the reconstructed $\mathrm{ARC} 2$ shows much improvement over its predecessor with respect to maintaining homogeneity over a long-term record. A large dry bias is evident in the original ARC1 monthly rainfall areal average from 1998 to 2000 that is not seen in the ARC2, GPCP, and CMAP data. This erroneous feature is likely attributed to the treatment of historical MFG imagery performed in the reprocessing of ARC1. Comparisons of mean annual GPCP and CMAP rainfall exhibit impressive agreement with the ARC2 from 1983 to 2009. Figure 2b also shows that the ARC2 closely follows GPCP and CMAP in terms of year-to-year mean changes in precipitation, with the exception that the ARC2 exhibited on average slightly less rainfall. This dryness becomes more evident when comparing the annual cycle of precipitation between the datasets in Fig. 2a. While the annual mean curves are very similar between all products, ARC2 maintains a greater decrease in mean rainfall after approximately June. By October, the ARC2 annual mean rainfall becomes more comparable with the GPCP and CMAP products relative to the upward seasonal trend and in total magnitude. The ARC1 annual cycle also follows this pattern, but remains drier overall. A second set of time series analyses was performed again using land-only rainfall over Africa to compare with the gauge-only PREC/L dataset (Figs. 2c,d). The ARC2 does well in capturing the interannual variability of rainfall similar to the GPCP, CMAP, and PREC/L data from 1983 to 2009. However, two key differences are again observed between the ARC2 and the GPCP, CMAP, and PREC/L datasets: 1) the ARC2 appears consistently drier during the Northern Hemisphere summer from 1983 to 2009 and 2) the rainfall magnitude in ARC2 remains consistently less relative to all other products on a year-to-year basis.

From 1983 to 2009, the long-term mean spatial distributions of ARC2, GPCP, CMAP, and PREC/L are compared and illustrated in Figs. 3a-d. After the ARC2 data were averaged onto a $2.5^{\circ}$ grid, they agree with the spatial means of the GPCP, CMAP, and PREC/L products. Despite some slight variations relative to the magnitude of mean rainfall over coastal areas in the Gulf of Guinea region and southwestern Indian Ocean, the overall distribution of the mean rainfall is largely consistent over Africa. Table 2 shows the annual and seasonal mean precipitation values, as well as the cross data correlation coefficients for all products (values in parentheses denote land-only rainfall). ARC2 maintains high correlations of $0.86,0.86$, and 0.82 with the GPCP, CMAP, and PREC/L datasets, respectively. However, a noticeable spread in the seasonal means is evident. This reflects the finding that the June-September time frame is when the ARC2 disagrees with the other products the most.

To diagnose the source region of the disagreement, spatial analyses of 3-month mean seasonal rainfall were then examined between the ARC2, GPCP, and CMAP data. Figures $4 a, b$ show that the greatest differences in mean July-September rainfall occur across the Gulf of Guinea region in Ethiopia and along the eastern coast of Madagascar. Because rainfall is at a minimum over Madagascar during the Northern Hemisphere summertime, we focus on validating rainfall estimates over the Gulf of Guinea region and over Ethiopia in order to diagnose the summer season discrepancy. In East Africa, the sparse distribution of GTS gauges especially in the higher elevations of Ethiopia has a negative impact on the performance of merged rainfall estimate products. In addition, it is noted that underestimations in these two regions have been reported in previous literature (Dinku et al. 2007; Herman et al. 1997). Specifically, the fixed brightness temperature threshold used in the GPI generally fails to capture warm-cloud precipitation processes over coastal and orographic regions of Africa. However, because this effect may be mitigated by local calibration associated with GTS data, we also focus on the availability of gauge reports.

\section{b. Monthly validation and GTS reporting}

Monthly rainfall means derived from monthly gauge measurements at several stations in the Gulf of Guinea 
a.

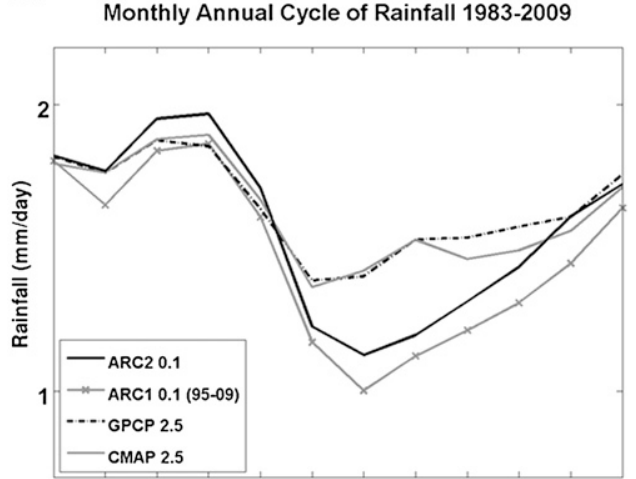

Jan Feb Mar Apr May Jun Jul Aug Sep Oct Nov Dec

b.

Annual Means of Areal Averaged Rainfall 1983-2009

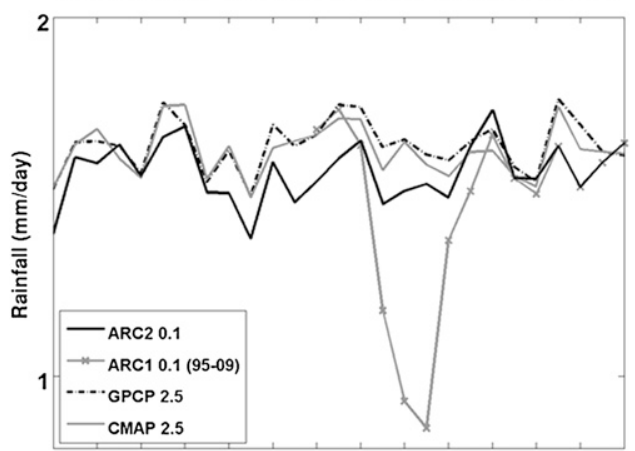

$\begin{array}{llllllllllllll}83 & 85 & 87 & 89 & 91 & 93 & 95 & 97 & 99 & 01 & 03 & 05 & 07 & 09\end{array}$
C.

Monthly Annual Cycle of Land-Only Rainfall 1983-2009

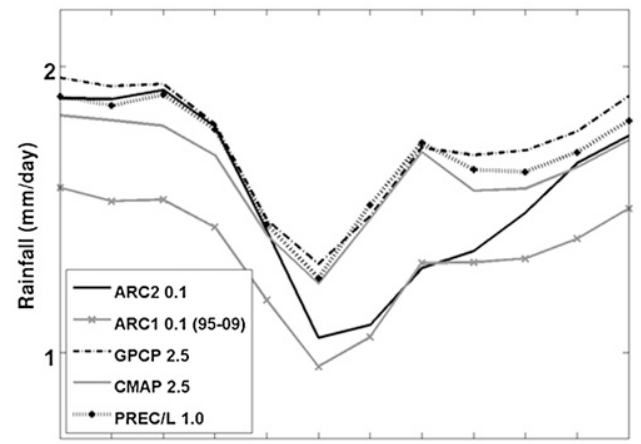

Jan Feb Mar Apr May Jun Jul Aug Sep Oct Nov Dec

d.

Annual Means of Land-Only Areal Averaged Rainfall 1983-2009

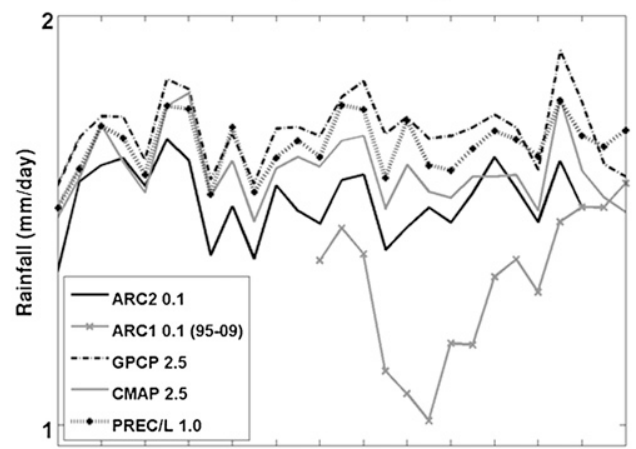

$\begin{array}{llllllllllllll}83 & 85 & 87 & 89 & 91 & 93 & 95 & 97 & 99 & 01 & 03 & 05 & 07 & 09\end{array}$

FIG. 2. Time series of (a) monthly annual cycle of rainfall, (b) annual means of areal-averaged rainfall, (c) monthly annual cycle of land-only rainfall, and (d) annual means of areal-averaged land-only rainfall for ARC2, ARC1, GPCP, CMAP, and PREC/L over Africa $\left(40^{\circ} \mathrm{S}-40^{\circ} \mathrm{N}\right.$ and $\left.20^{\circ} \mathrm{W}-55^{\circ} \mathrm{E}\right)$ from 1983 to 2009.

region of Africa were also used to validate the rainfall estimate datasets. These Gulf of Guinea gauge data are independent from the GTS observations in the region and were obtained from various meteorological services in Africa. They are hereinafter referred to as Guinean Rainfall Independent Data (GRID). The development of the GRID gauge dataset featured 248 rain gauges covering the Gulf of Guinea and the lower Sahel region of West Africa. GRID rainfall were computed over a unified $2.5^{\circ}$ grid and compared with the respective rainfall estimates for the 32 summer months of JuneSeptember from 1997 to 2004. This 8-yr period was used because it was the largest overlapping period available for validation. The goal of performing this monthly validation was to determine if summer disagreements between the ARC2 and GPCP, CMAP, and PREC/L were either one of the following: 1) an artifact that was introduced during the reprocessing of historical ARC2 or 2) a systematic dry bias in the ARC2 dataset.

Scatterplot analyses and validation metrics between the GRID data and the ARC2, GPCP, CMAP, and
PREC/L data are illustrated in Figs. 5a-d. All products showed reasonable agreement with the independent gauge data; however, validation scores determined that the GPCP, CMAP, and PREC/L products overall outperformed the ARC2 rainfall estimates. While all products showed a tendency to underestimate high rainfall amounts observed in the GRID data, the ARC2 yielded the highest root-mean-square error (RMSE) and qualitative bias (perfect bias score $=1$ ) during the 32-month validation period relative to the other products. This validation suggested that the summer dry bias in the ARC2 dataset is systematic over the 8-yr period.

Remarkable variations in the GTS daily reporting rates across the African continent from 1983 to 2009 were found. A closer look at the daily GTS reporting rates over the Gulf of Guinea region revealed that GTS stations in The Gambia, Guinea-Bissau, Guinea, Sierra Leone, and Nigeria reported only $30 \%$ of the time from 1983 to 2009. Throughout East Africa, GTS reporting rates were generally higher, with Ethiopia ranging 
a.

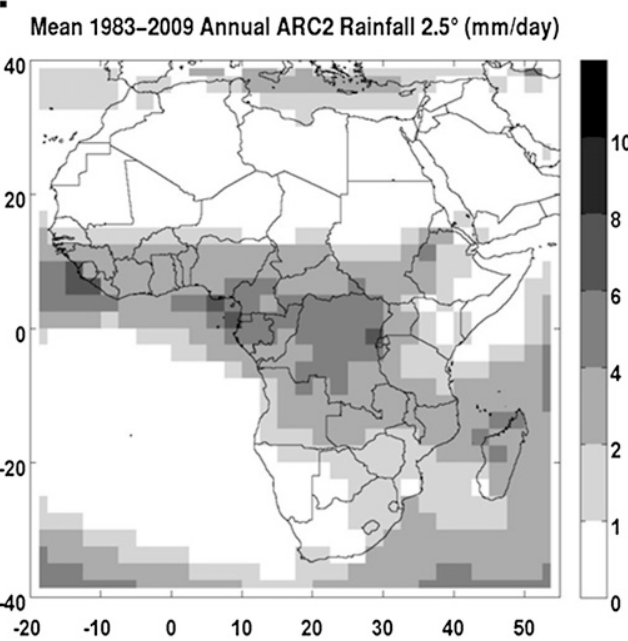

C.

Mean 1983-2009 Annual CMAP Rainfall $2.5^{\circ}$ (mm/day)

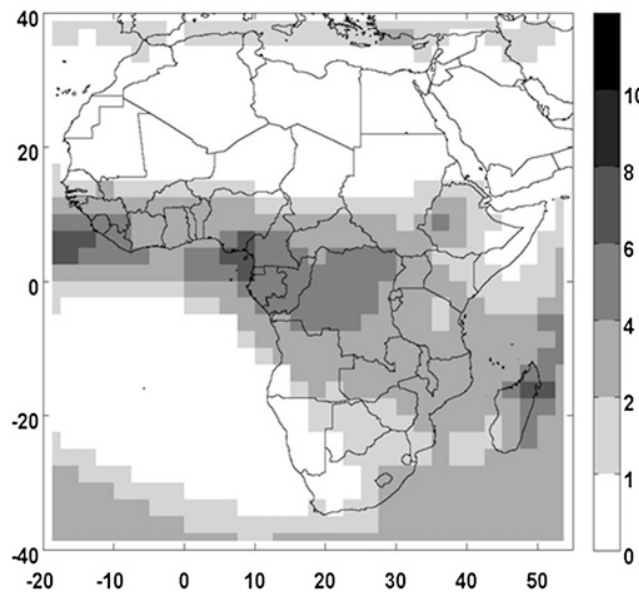

b.

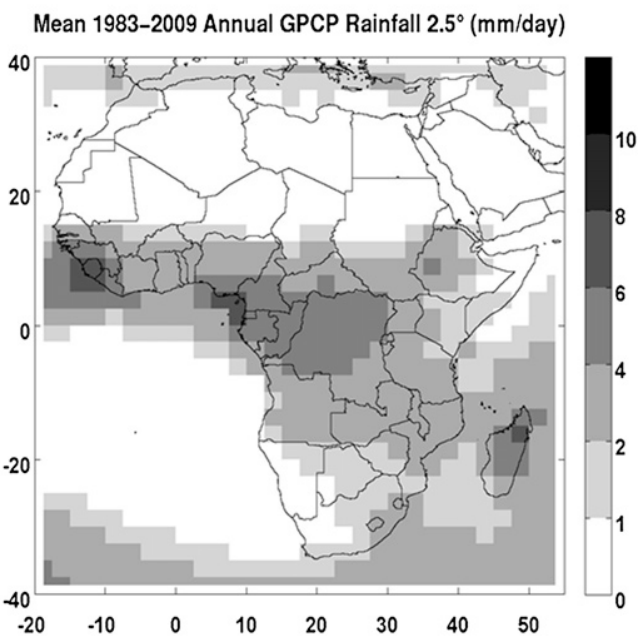

d.

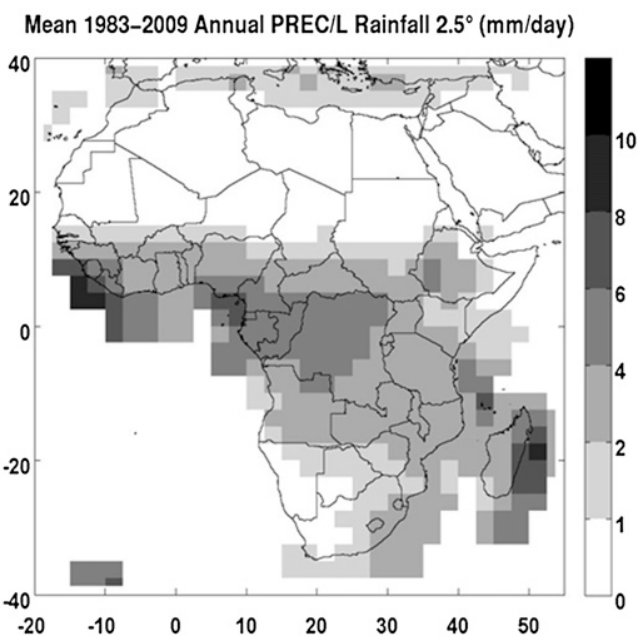

FIG. 3. Spatial mean of annual (a) ARC2, (b) GPCP, (c) CMAP, and (d) PREC/L rainfall (mm day ${ }^{-1}$ ) at $2.5^{\circ}$ resolution over Africa from 1983 to 2009.

between $40 \%$ and $70 \%$ of the time from 1983 to 2009 . During the 32-month validation period, the lowest reporting rates were $6 \%$ in Guinea-Bissau and Sierra Leone, which ranked among the lowest relative to all other countries in Africa. The linkage between GTS reporting percentages and validation scores associated with the ARC2 and GRID data are illustrated in Figs. 6a-c. Areas in the lower Gulf of Guinea region with low GTS reporting rates are clearly collocated over areas with high RMSE, and areas with low correlations between the ARC2 and GRID data. Conversely, areas with higher reporting rates over $70 \%$ farther north in the Sahel are associated with lower RMSEs, and higher correlations. A histogram was generated to derive the relationship between GTS reporting rates and the corresponding absolute error seen in the validation between the ARC2 and GRID data. Figure 7 shows that as GTS reports decrease throughout parts of the Gulf of Guinea region, the mean absolute error observed with the ARC2 increases. This inverse relationship suggests that the unavailability of gauge data in the Gulf of Guinea region may play a major role in the estimation performance in the new ARC2 dataset, and may also explain the observed summer dryness relative to the other longterm precipitation datasets on a monthly scale.

\section{c. Daily validation}

In the following we compare daily ARC2 with other daily satellite precipitation products that resemble more closely the spatial and temporal resolutions of the ARC2. We have selected the TRMM Multisatellite Precipitation Analysis 3B42, version 6 (3B42v6), rainfall 
TABLE 2. Product intercomparison of (top) annual and seasonal means and (bottom) product correlation matrix of monthly mean rainfall $(n=324)$ from 1983 to 2009. Land-only values are denoted in parentheses.

\begin{tabular}{|c|c|c|c|c|c|c|}
\hline & Annual & DJF & MAM & \multicolumn{2}{|c|}{ JJA } & SON \\
\hline ARC2 & $1.57(1.55)$ & $1.77(1.85)$ & $1.88(1.71)$ & \multicolumn{2}{|c|}{$1.18(1.15)$} & $1.45(1.50)$ \\
\hline ARC1 (1995-2009) & $1.47(1.34)$ & $1.70(1.54)$ & $1.77(1.38)$ & \multicolumn{2}{|c|}{$1.10(1.11)$} & $1.32(1.35)$ \\
\hline RFE2 (2001-09) & $1.51(1.44)$ & $1.70(1.62)$ & $1.73(1.42)$ & \multicolumn{2}{|c|}{$1.20(1.25)$} & $1.40(1.48)$ \\
\hline GPCP & $1.64(1.72)$ & $1.78(1.93)$ & $1.79(1.73)$ & \multicolumn{2}{|c|}{$1.44(1.50)$} & $1.57(1.72)$ \\
\hline CMAP & $1.63(1.62)$ & $1.76(1.80)$ & $1.81(1.63)$ & \multicolumn{2}{|c|}{$1.44(1.47)$} & $1.50(1.59)$ \\
\hline \multirow[t]{2}{*}{$\mathrm{PREC} / \mathrm{L}$} & (1.68) & $(1.86)$ & $(1.71)$ & & $.50)$ & $(1.66)$ \\
\hline & $\mathrm{ARC} 2$ & ARC1 (1995-2009) & RFE (2001-09) & GPCP & CMAP & $\mathrm{PREC} / \mathrm{L}$ \\
\hline $\mathrm{ARC} 2$ & - & $0.83(0.78)$ & $0.97(0.84)$ & $0.86(0.85)$ & $0.86(0.79)$ & $(0.82)$ \\
\hline ARC1 (1995-2009) & $0.83(0.78)$ & - & $0.95(0.81)$ & $0.73(0.71)$ & $0.74(0.71)$ & $(0.71)$ \\
\hline RFE2 (2001-09) & $0.97(0.84)$ & $0.95(0.81)$ & - & $0.90(0.90)$ & $0.90(0.90)$ & $(0.87)$ \\
\hline GPCP & $0.86(0.85)$ & $0.73(0.71)$ & $0.90(0.90)$ & - & $0.94(0.93)$ & $(0.91)$ \\
\hline CMAP & $0.86(0.79)$ & $0.74(0.71)$ & 0.90 & $0.94(0.93)$ & - & $(0.89)$ \\
\hline $\mathrm{PREC} / \mathrm{L}$ & (0.82) & $(0.71)$ & $(0.87)$ & (0.91) & $(0.89)$ & - \\
\hline
\end{tabular}

estimates (Huffman et al. 2007, 2010) and the CPC's morphing technique $(\mathrm{CMORPH})$ rainfall estimator (Joyce et al. 2004) from 2003 to 2010. Both of these products differ from the ARC2, as they utilize estimation techniques that ingest IR and microwave data on an intradaily basis. Specifically, the 3B42v6 uses calibrated microwave data to generate IR precipitation estimates while incorporating non-real-time gauge adjustments. Precipitation estimates from CMORPH are solely microwave based but use motion fields from IR data to interpolate between rainfall fields and do not include any gauge input. These 3-hourly products are quasi global at $0.25^{\circ}$ resolution, and were summed to daily totals to match the ARC2's 0600-0600 UTC 24-h estimate period. Similar to the monthly validation in the previous section, our methods consisted of the pairing between gauge data on a daily, unified $0.25^{\circ}$ daily resolution grid and the respective daily pixels for all three high-resolution satellite rainfall products. We first present daily validation results using GTS gauge data during 2010 followed by validation results using nonGTS gauge measurements from West Africa and Ethiopia. Independent daily gauge data collected from 133 stations in the Sahel region of West Africa were acquired for the summer months (June-September) from 2008 to 2010 (366 days), and from 30 stations in Ethiopia from 2003 to 2007 (610 days). These daily independent gauge datasets are hereinafter referred to as WAGA and EGA, respectively.

Using GTS gauge data in 2010, daily RMSE and correlation scores were computed for each product, and were evaluated over a seasonal and annual basis, as well as over the continent and common regions of Africa. The pairing of RMSE and correlation scores for each scenario is illustrated in the form of a scatterplot. From
Fig. 8, ARC2 clearly shows higher validation scores than 3B42v6 and CMORPH for all regions and time scales. The 3B42v6 and CMORPH perform the poorest over West Africa during the April-June (AMJ) and JulySeptember (JAS) seasons, with RMSE scores nearly twice that observed with ARC2.

For daily validation using non-GTS gauge measurements, the ARC2 validates reasonably well over the Sahel region of West Africa. As illustrated in Figs. 9a-d, the ARC2 yielded the lowest bias and RMSE scores and second highest correlation $(0.46)$ relative to the 3B42v6 and CMORPH products. Although CMORPH exhibits the highest correlation when validated against WAGA data, scatterplot analysis in Fig. 9d shows that CMORPH generally overestimates precipitation in West Africa, and possesses the highest bias and RMSE scores. These validations over West Africa are also consistent with the findings of Jobard et al. (2011), where it is also noted that the GPI, by itself, has outperformed 3B42v6 and CMORPH rainfall estimates over the West African monsoon region. In Ethiopia, however, validation results for the ARC2 are not as impressive. As seen from Figs. 9f-h, CMORPH showed the highest correlations and lowest bias, whereas the ARC2 yielded the lowest correlation (0.31) and highest RMSE score from 2003 to 2007. The ARC2's tendency to underestimate rainfall is enhanced when topographical data are used in the validation. After masking stations with elevations below $2500 \mathrm{~m}$ in the EGA dataset, validation results for the ARC2 showed a considerable increase in the bias scores, whereas $3 \mathrm{~B} 42 \mathrm{v} 6$ and CMORPH bias scores remained the approximately the same. These results suggest some sensitivity in the estimation performance of the ARC2 over complex topography. 
a. ARC2 - GPCP $2.5^{\circ}$ Mean Jul-Sep Rainfall 1983-2009

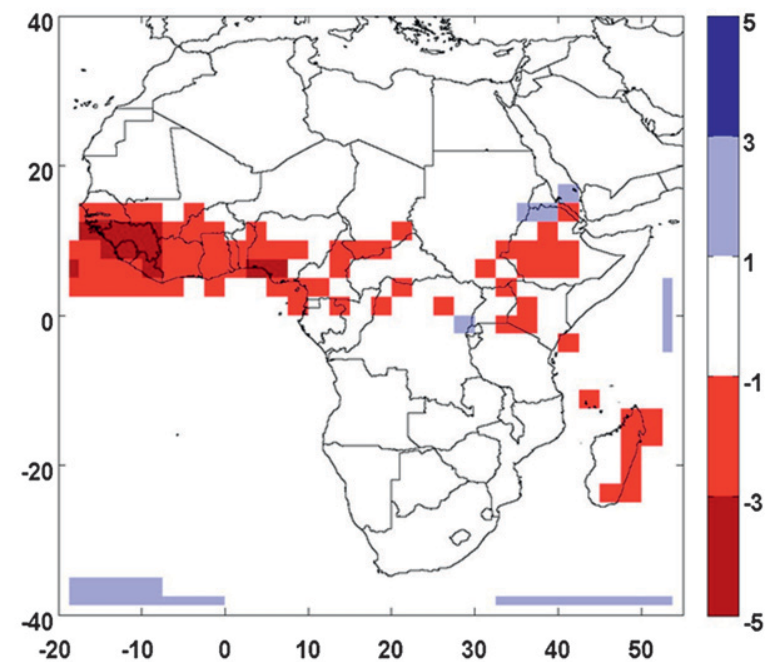

b. ARC2 - CMAP $2.5^{\circ}$ Mean Jul-Sep Rainfall 1983-2009

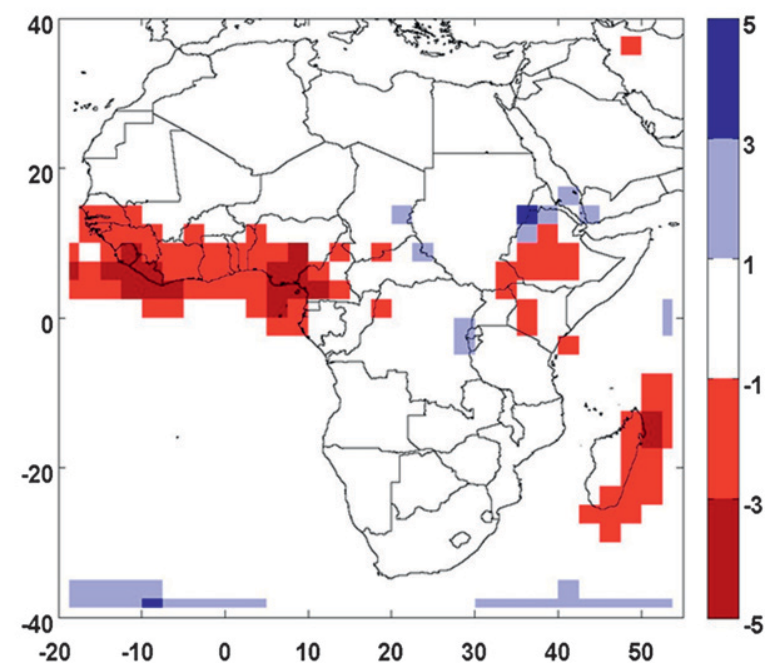

FIG. 4. Maps of differenced mean seasonal (JAS) rainfall $\left(\mathrm{mm} \mathrm{day}{ }^{-1}\right.$ ) of (a) ARC2 - GPCP and (b) ARC2 - CMAP over Africa $\left(40^{\circ} \mathrm{S}-40^{\circ} \mathrm{N}\right.$ and $\left.20^{\circ} \mathrm{W}-55^{\circ} \mathrm{E}\right)$ from 1983 to 2009.

From these validation results over Ethiopia, we can make the following observations: 1) CMORPH and $3 \mathrm{~B} 42 \mathrm{v} 6$ outperform the $\mathrm{ARC} 2$ in this region, despite the fact that these products do not ingest any real-time gauge data for local calibration in the final rainfall estimates, and 2) GTS gauge reporting rates in Ethiopia are much higher than for the Gulf of Guinea region. These facts suggest that lower precipitation over Ethiopia is likely the result of the RFE2 and ARC2's inability to adequately capture warm-cloud precipitation processes over complex topography, as supported by the findings of Dinku et al. (2007). Although this would imply that the ARC2 estimates can be improved, examinations of attributing differences between various precipitation processes would require experimentation and modification of the RFE-ARC algorithm. This work may be performed in the future but is outside the scope of this paper.

\section{Operational climate monitoring}

One main advantage of the new ARC2 dataset is that it is readily applicable to operational climate monitoring. The daily availability of the ARC2 has allowed the generation of numerous products that provide important insight into the evolution of rainfall totals and anomalies at weekly, dekadal (10 day), monthly, and seasonal time scales, all of which are critical to decision making in agriculture, water resources, and food security. Many ARC2 anomaly-based products are tailored to time scales that encompass agricultural cycles related to food security, including its hydrological aspects. It is here that the $\mathrm{ARC} 2$ has proved most useful in planning for emergency response.

The following case studies in the greater Horn of Africa and southern Africa show how the ARC2 is used in operational climate monitoring for food security. For comparisons on a daily operational basis, we have included daily gauge measurements (GTS and independent) and TRMM 3B42RT (real time) rainfall estimates (Huffman et al. 2010) due to their availability in operational monitoring, and for 3B42v6 climatological data (1998-present), which may be used to generate anomalies. Although CMORPH is considered as an operational product, its record length was considered insufficient (2003-present) to generate anomaly fields and was not used. Validation with gauge data consisted of a point to the closest pixel analysis. For monthly comparisons, we again used the GPCP and CMAP products.

The first regional case study examines the East African drought of 2010-11, which has been characterized by the international community as the "worst in the last 60 years," triggering famine and resulting in the displacement of thousands of people. The onset of the drought began after a failed October-December (OND) rainfall season in 2010 throughout Somalia, Ethiopia, and Kenya, followed by very poor March-May (belg) 2011 rains in the region. Figures 10a,b illustrate the spatial distribution of $\mathrm{ARC} 2$ and $3 \mathrm{~B} 42 \mathrm{RT}$ seasonal rainfall anomalies for OND. At the end of 2010, both products showed reasonable spatial agreement in East Africa, with the greatest precipitation deficits (100-300 mm) concentrated across the pastoral areas of eastern Kenya and southern Somalia. Time series analyses depicting the evolution of daily rainfall in Mandera, Kenya, between ARC2 and 3B42RT (Figs. 10c,d) showed that this 
a.

GPCP vs. GRID: Jun - Sep, 1997-2004 (n=1274)

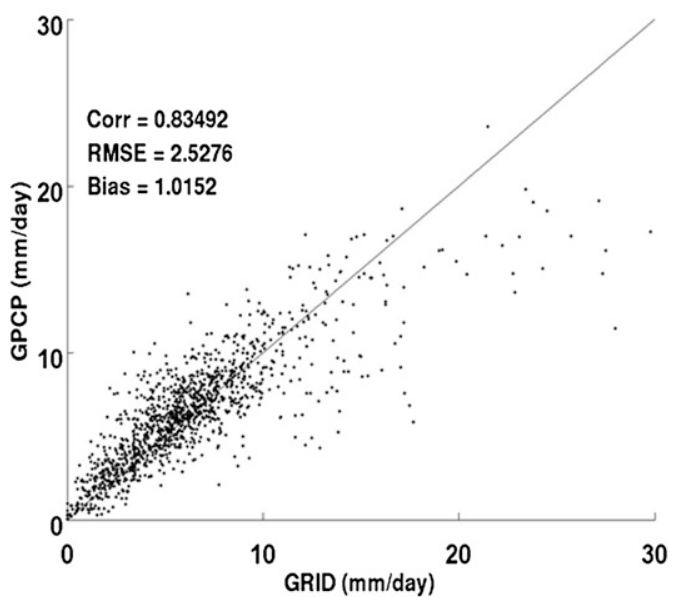

C.

PREC/L vs. GRID: Jun - Sep, 1997-2004 (n=1274)

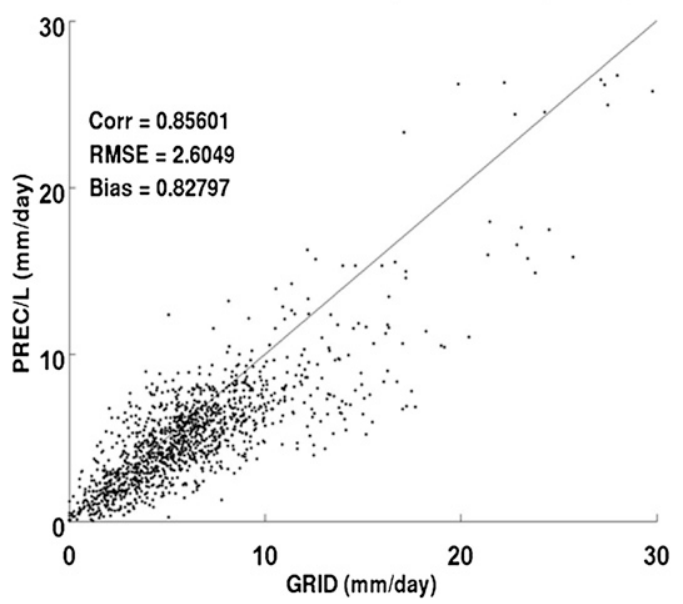

b.

CMAP vs. GRID: Jun - Sep, 1997-2004 ( $n=1274)$

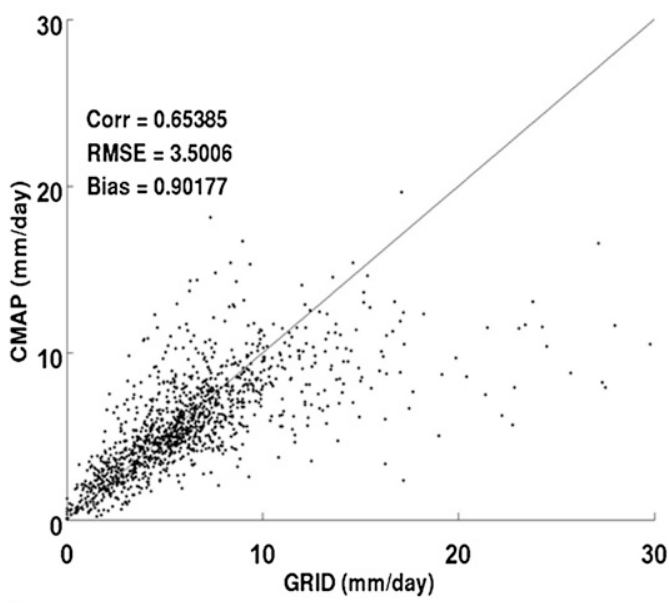

d.

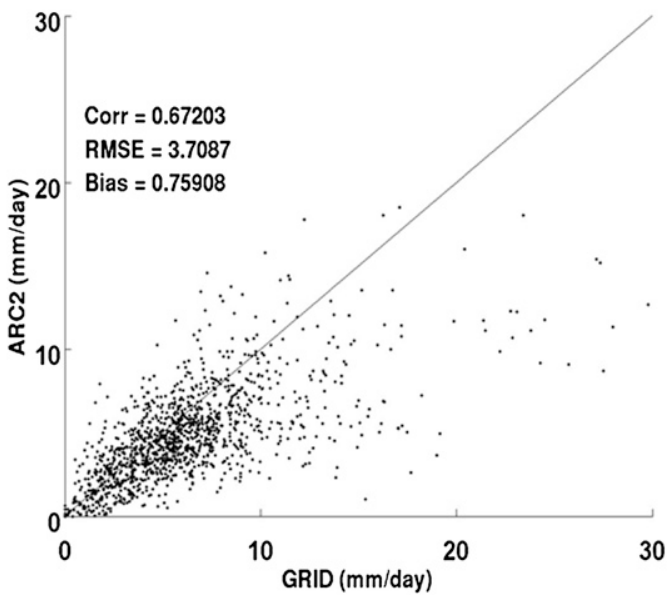

FIG. 5. Scatterplots of mean dekadal rainfall $\left(\mathrm{mm} \mathrm{day}^{-1}\right)$ averaged over a $2.5^{\circ}$ unified grid between GRID and (a) GPCP, (b) CMAP, (c) PREC/L, and (d) ARC2 during JAS from 1997 to 2004.

area received only 2 days of rainfall in the amount of $18 \mathrm{~mm}$ for the entire season. This meager amount accounted for approximately $15 \%$ of the average rainfall according to both the ARC2 and 3B42 daily climatologies for OND. Comparison with GTS gauge measurements in Mandera showed a higher amount, with 3 days of rain totaling $54 \mathrm{~mm}$, which equated to $\sim 40 \%$ of the OND gauge average. Based on this, both operational products underestimated the frequency and magnitude of the seasonal rains in late 2010; however, both were able to capture the total absence of rainfall from midNovember to December that reportedly led to livestock losses and depleted water resources in eastern Kenya according to FEWS-NET. Farther west in the major maize-producing area of Nyahururu, Kenya, both the $\mathrm{ARC} 2$ and 3B42RT differ with respect the observed and climatological rainfall totals, as well as the evolution of seasonal rainfall (Figs. 10e,f). At the start of the season, the 3B42RT depicted favorably above-average rainfall throughout October, followed by periods of suppressed rainfall leading to moderate seasonal rainfall deficits. A different seasonal evolution pattern was observed with ARC2, which showed a late start to the season, followed by light and inconsistent precipitation throughout the remainder of the season. Validation with an independent (non-GTS) gauge in Nyahururu showed better agreement with ARC2 than 3B42RT, with total OND precipitation amounts of 79,51 , and $155 \mathrm{~mm}$ for the gauge, $\mathrm{ARC} 2$, and 3B42RT, respectively. The 3B42RT dataset had overestimated October rainfall by nearly twice as much, with a considerably higher local climatological mean for OND. 
a.

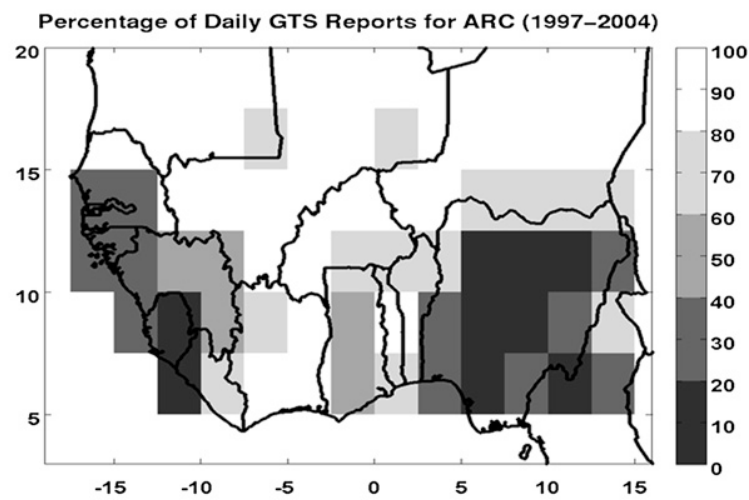

b.

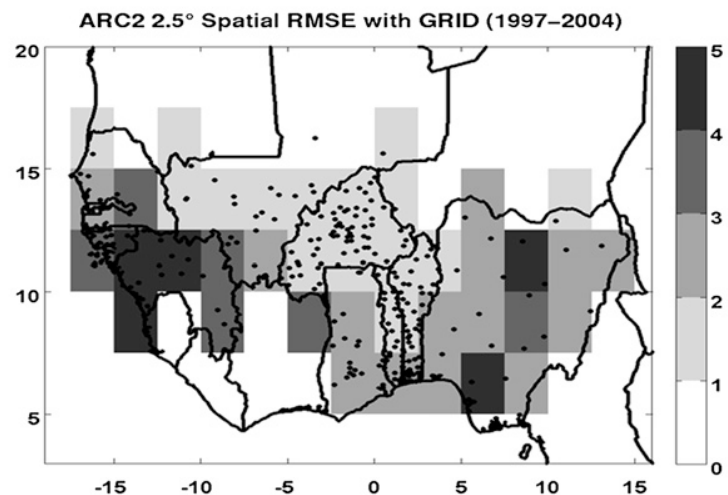

C.

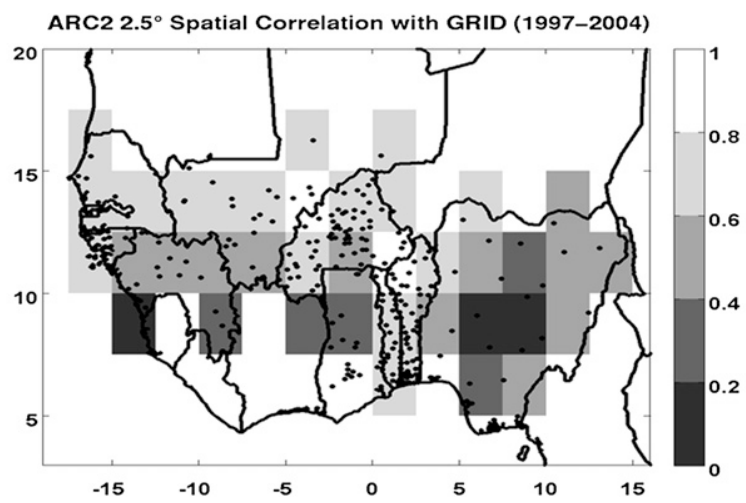

FIG. 6. (a) Analysis of GTS reporting rate percentages computed over a $2.5^{\circ}$ unified grid compared with the GRID spatial distribution of (b) RMSE and (c) correlation statistics between ARC2 and GRID during JAS from 1997 to 2004.

The second regional study examines the southern African monsoon season of 2008-09. Based on the spatial distribution of $\mathrm{ARC} 2$ and 3B42RT anomalies in Figs. 11a,b, heavy precipitation accumulations over continental southwestern Africa resulted in an aboveaverage $(100 \%-200 \%$ of normal) monsoon season over many rain-fed agricultural parts of southern Angola, northern Namibia, and the Caprivi Strip region. Daily evolutions of $\mathrm{ARC} 2$ and 3B42RT seasonal rainfall in Ondangwa in northern Namibia exhibited great agreement from October 2008 to May 2009 (Figs. 11c,d). Both depicted a normal start in their monsoon rains followed by the onset of an early season dry spell with three consecutive weeks of no rainfall beginning in late December into mid-January. This dryness occurred when monsoon rains were expected to be at their maximum after crops had been planted for the season, and led to a rapid weakening of moisture surpluses. After this dry spell, Ondangwa observed the return of the heavy, persistent rainfall resulting in anomalously wet conditions for five consecutive weeks. The heavy rainfall reportedly led to elevated water levels along the Okavango River basin, resulting in numerous localized flooding events, displaced people, and damage to both crops and infrastructure in northern Namibia. Validation with local gauge data were consistent with the timing and severity of anomalous dry and wet spell events, which had negatively impacted agricultural activities in the region.

On the other side of the continent, much of southeastern Africa experienced more nearly neutral conditions for the season. In Blantyre, Malawi, time series analyses of both ARC2 and 3B42RT rainfall (Figs. 11e,f) showed a normal start of the rainy season. During the middle of the season, intermittent and low rainfall totals throughout February and early March resulted in anomalous dryness in southern Malawi, as there were concerns over developing moisture stress for crops. By April, however, there is a noticeable divergence in the products, with increased rainfall returning in May for 3B42RT, and little rainfall estimated by ARC2. As a result, above-average conditions were depicted by 3B42RT, and below-average conditions were depicted by ARC2 for the entire season. Although the departures from the seasonal average were marginal between both products, the total observed and accumulative rainfall amounts were quite different. Validation with local gauge data in Blantyre showed better correspondence with ARC2 in terms of seasonal totals, climatology, and in capturing the number of high rainfall days over the course of the season. The 3B42RT dataset had overestimated both the seasonal rainfall total by nearly $200 \mathrm{~mm}$ and had a wetter climatology by over $100 \mathrm{~mm}$ relative to the local gauge data.

Extending from the southern Africa case study, Fig. 12 illustrates the evolution of ARC2 rainfall anomalies during the peak of the 2008-09 southern Africa monsoon [i.e., December-February (DJF)] on a dekadal time scale. In mid-December 2008, widespread rainfall surpluses developed over the Zambezi River basin, encompassing southern Zambia, northern Zimbabwe, and central Mozambique. Typically, the persistence of heavy rainfall in this region results in flooding along the Zambezi River, displacing many local populations. 


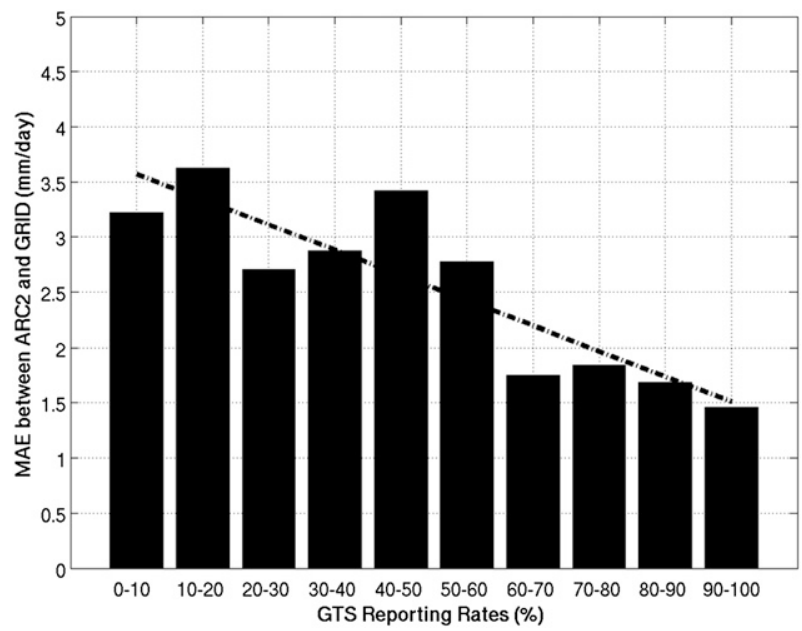

FIG. 7. Histogram of binned GTS reporting percentages and the corresponding areas of mean absolute error between ARC2 and GRID during JAS from 1997 to 2004.

However, drier than average rainfall in late January through the end of February helped mitigate flood concerns for many areas along the Zambezi River. In comparing ARC2 with GPCP and CMAP from December to February, all three anomaly products showed excellent agreement on monthly and seasonal time scales (Fig. 13). In February 2009, a rainfall anomaly dipole was observed between all datasets, with positive rainfall anomalies throughout the southwest, and negative rainfall anomalies encompassing much of the southeastern portion of the continent. The negative anomalies in the southeast during February offset the positive anomalies that were observed earlier in December, resulting in large rainfall surpluses throughout southern Angola and northern Namibia for the entire December-February period.

Combined with RFE2, GFS forecast data, and other weather and agricultural products, the daily ARC2 rainfall analyses are predominantly used to generate a weekly regional hazards outlook for USAID/FEWSNET. This weekly product outlines, discusses, and illustrates important weather and climate phenomena, which are likely to impact agricultural development in Africa. The regional hazard outlook is CPC's main contribution to decision making in food security in collaboration with USAID/FEWS-NET. It is also distributed to a global list of users.

\section{Conclusions}

This paper describes a new, operational rainfall climatology from 1983 to the present. Historical gauge and IR data were collected and were reprocessed using the

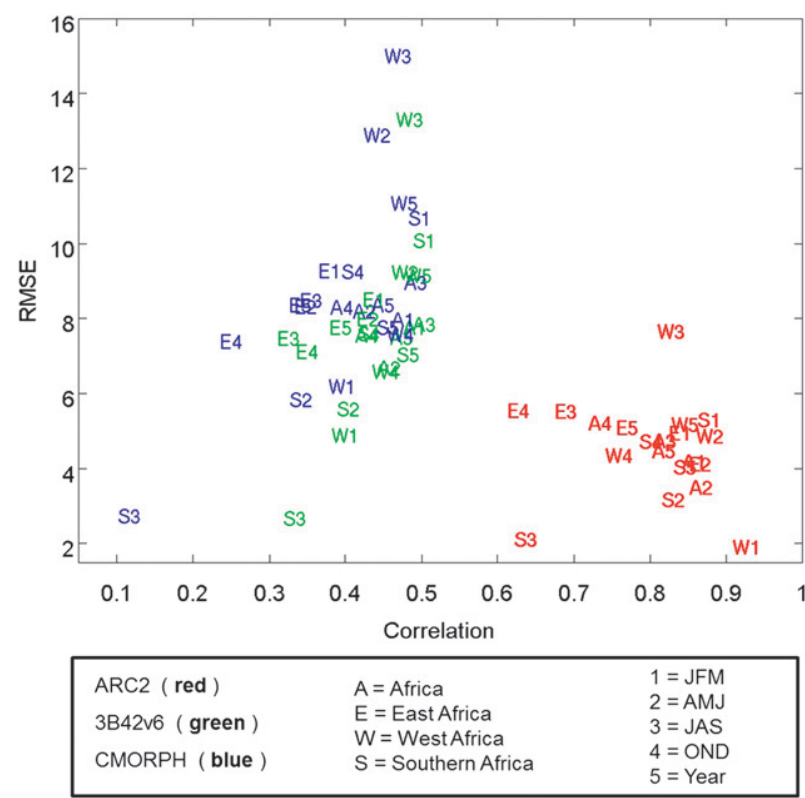

FIG. 8. Scatterplot of daily correlation ( $x$ axis) and RMSE ( $y$ axis) scores between 2010 GTS gauge measurements and ARC2 (red), 3B42v6 (green), and CMORPH (blue) rainfall estimates, where $\mathrm{A}=$ all Africa $\left(40^{\circ} \mathrm{S}-40^{\circ} \mathrm{N}, 20^{\circ} \mathrm{W}-55^{\circ} \mathrm{E}\right), \mathrm{E}=$ East Africa $\left(12^{\circ} \mathrm{S}-18^{\circ} \mathrm{N}, 26^{\circ}-52^{\circ} \mathrm{E}\right), \mathrm{W}=$ West Africa $\left(3^{\circ}-18^{\circ} \mathrm{N}, 18^{\circ} \mathrm{W}-20^{\circ} \mathrm{E}\right)$, $\mathrm{S}=$ southern Africa $\left(35^{\circ}-5^{\circ} \mathrm{S}, 10^{\circ}-52^{\circ} \mathrm{E}\right)$, and $1=\mathrm{JFM}$ (90 days), $2=$ AMJ (91 days), $3=$ JAS (92 days), $4=$ OND (92 days), and $5=$ entire year (365 days)

operational RFE2 algorithm at CPC. The ARC2 data are from 1983 to the present and are available on a daily basis.

A comparison between ARC1 and ARC2 data showed that the new ARC eliminated a large bias from 1998 to 2000, which significantly improved data quality and long-term stability. The improved consistency over an extended dataset record was the primary motivation for developing ARC2 at CPC. Comparisons between the ARC2 and the GPCP, CMAP, and PREC/L longterm monthly precipitation datasets showed that the mean spatial distribution, annual cycle, and interannual variability of rainfall in ARC2 are quite consistent with the four datasets. However, ARC2 exhibits a dry bias that is consistently seen during the Northern Hemisphere summer. The monthly validation between the independent (non GTS) gauge and the ARC2, GPCP, CMAP, and $\mathrm{PREC} / \mathrm{L}$ products shows reasonable agreement with the GRID data, with a tendency to underestimate rainfall relative to independent gauge observations with a bias score of 0.76 . The historical evaluation of GTS input data over Africa shows that the daily reporting percentage of GTS gauges varies considerably from country to country, with the lowest reporting rates of less than $30 \%$ found in countries located in the Gulf of Guinea region. This 
a.

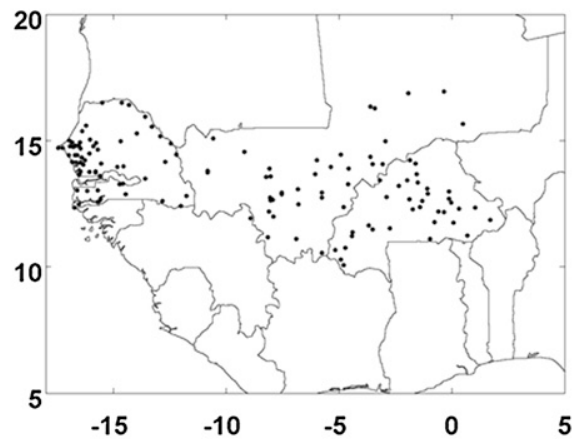

b.
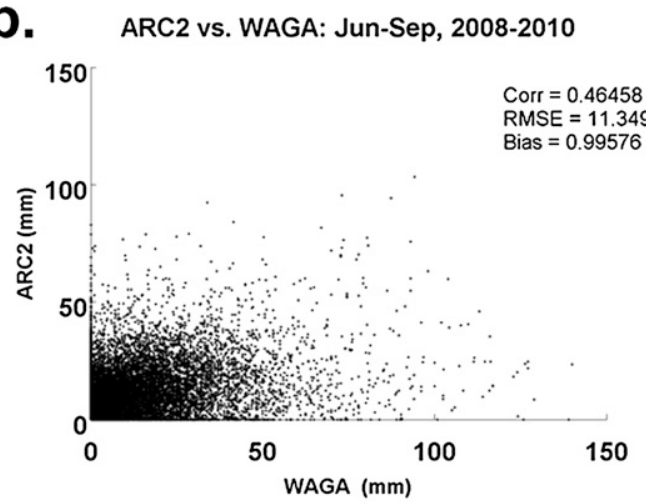

C. 3B42v6 vs. WAGA: Jun-Sep, 2008-2010

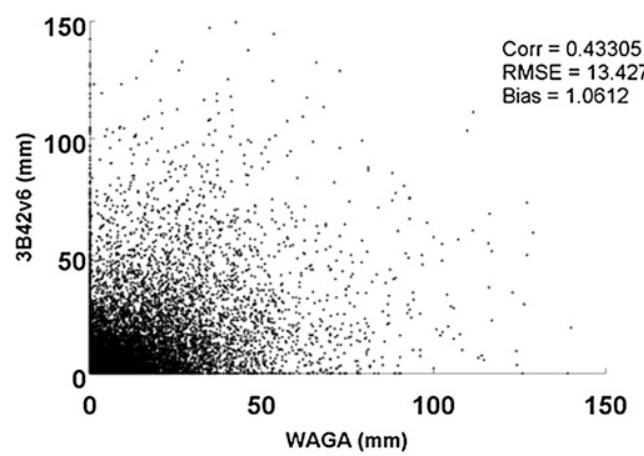

d. CMORPH vs. WAGA: Jun-Sep, 2008-2010

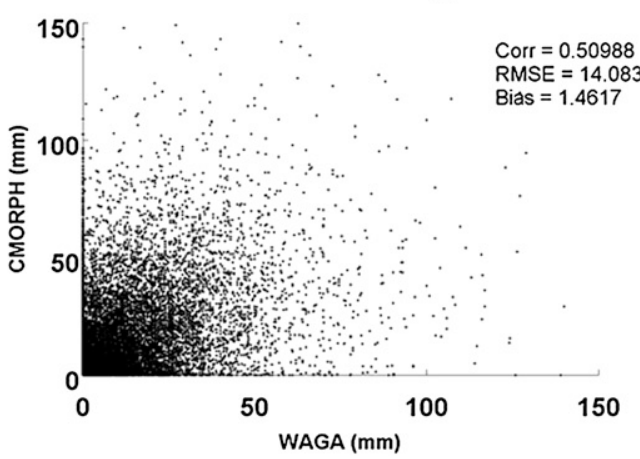

e. EGA Gauge Distribution

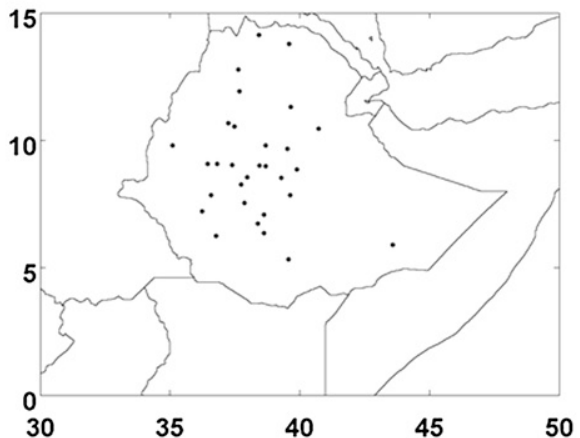

f. ARC2 vs. EGA: Jun-Sep, 2003-2007

\section{0}

150

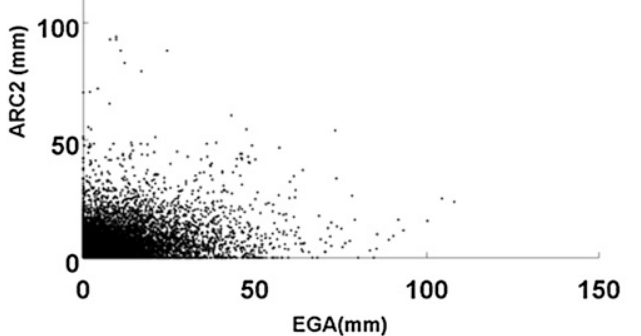

g.

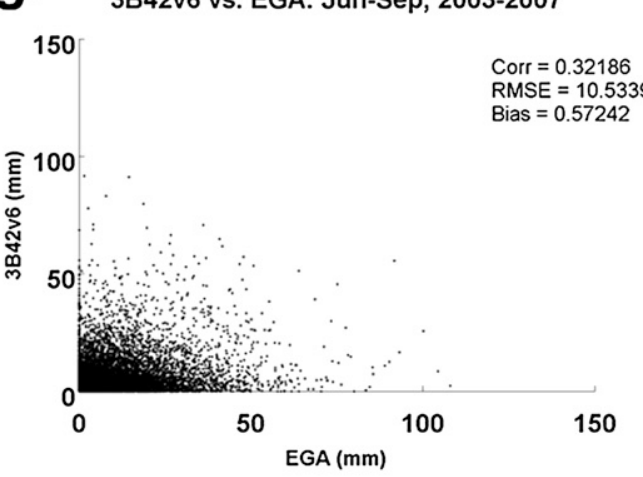

h. CMORPH vs. EGA: Jun-Sep, 2003-2007

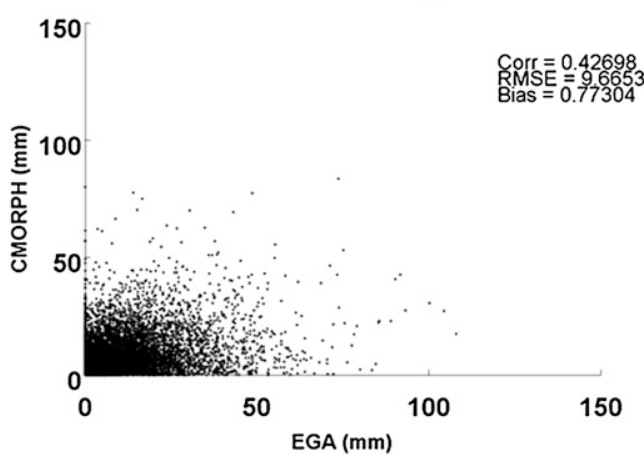

FIG. 9. Map of (a) WAGA gauge distribution, and daily validation scatterplots for (b) ARC2, (c) 3B42v6, (d) CMORPH, and (e) map of the EGA gauge distribution, as well as daily validation scatterplots for (f) ARC2, (g) 3B42v6, and (h) CMORPH. 
a.

ARC2 Rainfall Anomaly (mm): Oct 01, 2010 to Dec 31, 2010

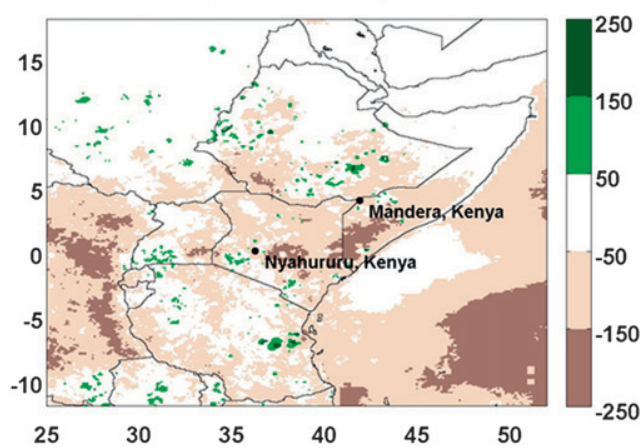

C.

C. ARC2 Rainfall at: Mandera, Kenya Oct 01, 2010 to Dec 31, 2010

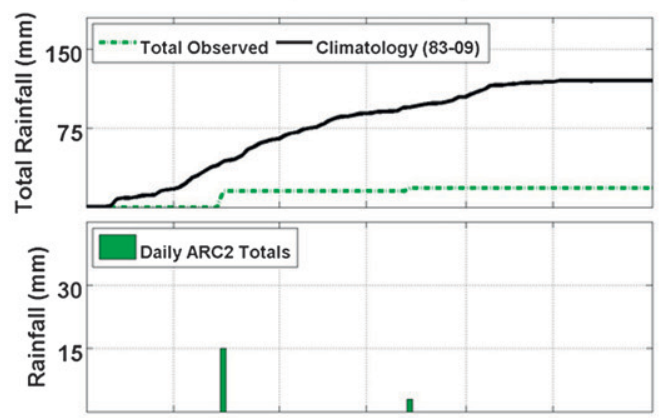

01-Oct 15-Oct 01-Nov 15-Nov 01-Dec 15-Dec

e.

ARC2 Rainfall at: Nyahururu, Kenya Oct 01,2010 to Dec 31, 2010

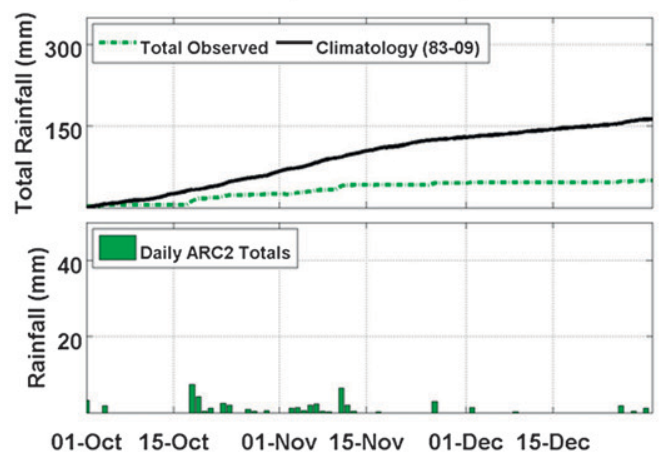

b. 3B42RT Rainfall Anomaly ( $\mathrm{mm}$ ): Oct 01, 2010 to Dec 31, 2010

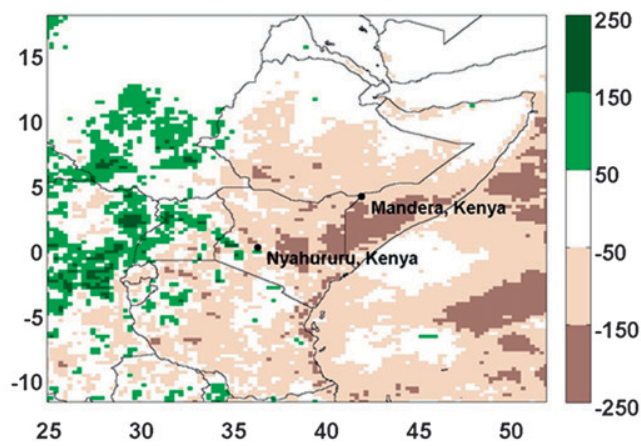

d.

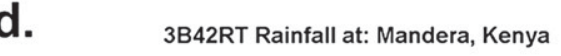
Oct 01, 2010 to Dec 31, 2010

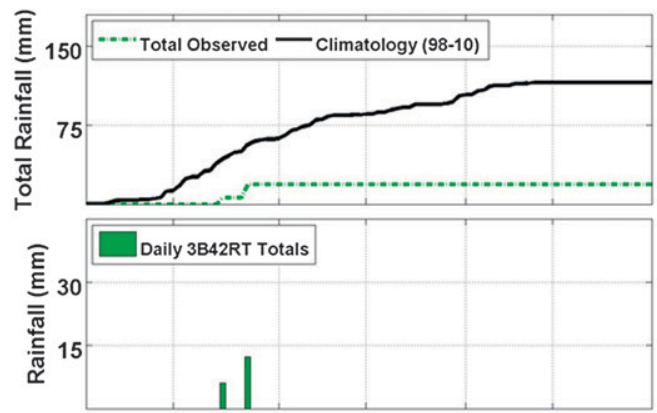

01-Oct 15-Oct 01-Nov 15-Nov 01-Dec 15-Dec

f. 3B42RT Rainfall at: Nyahururu, Kenya Oct 01, 2010 to Dec 31, 2010

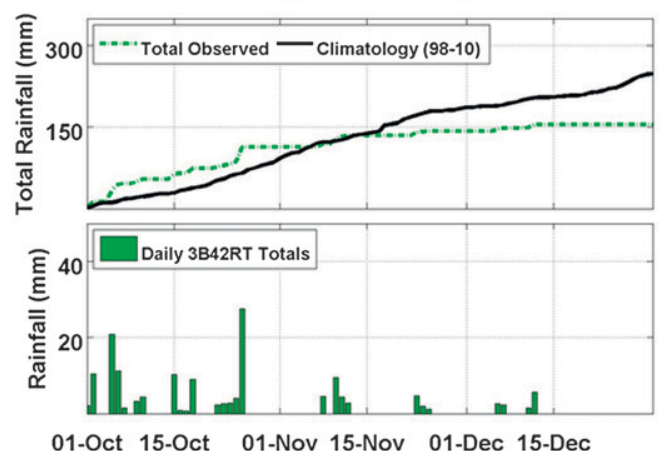

FIG. 10. Map of (a) ARC2 rainfall anomaly (mm), (b) 3B42RT total rainfall anomaly (mm), and observed and accumulative (c) ARC2 and (d) 3B42RT rainfall time series from Mandera, and (e) ARC2 and (f) 3B42RT rainfall time series from Nyahururu, for the East African rainy season (1 Oct-31 Dec 2010).

suggests that the absence of daily gauge data in the Gulf of Guinea region may explain the reoccurring summer dry bias observed in the new ARC2 dataset, as the lack of in situ measurements would impede any local adjustment of the satellite estimate. The unavailability of gauge data is not an issue for GPCP and CMAP due to the delay in their processing and the fact that they are monthly datasets.

Daily validation results suggest that there are strengths and weaknesses associated with the daily rainfall estimation products over various regions and seasons of Africa. Using independent gauges from the 
a.

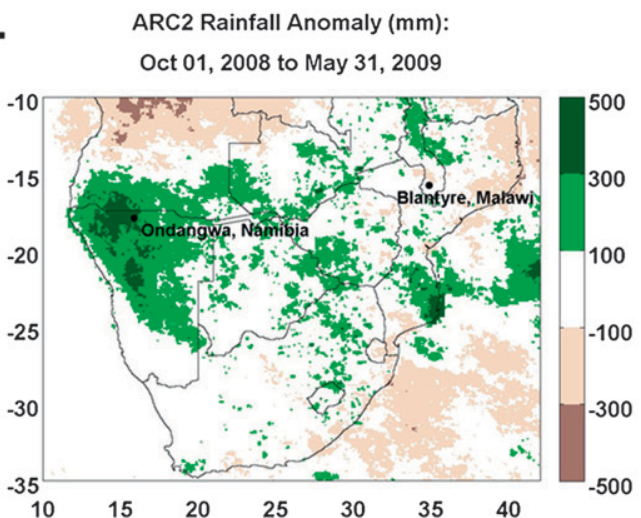

C.

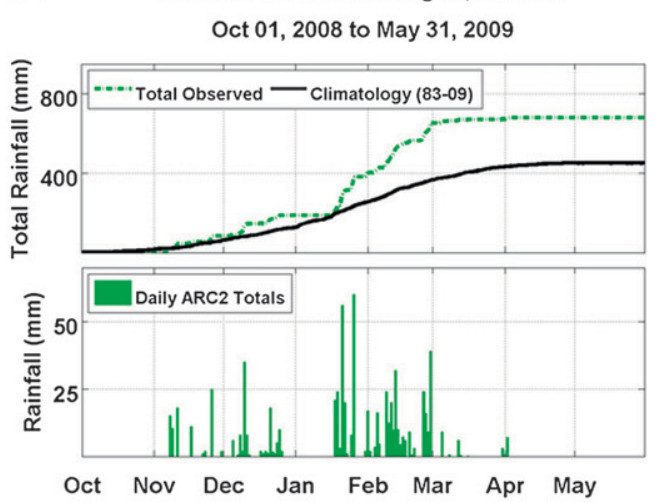

e.

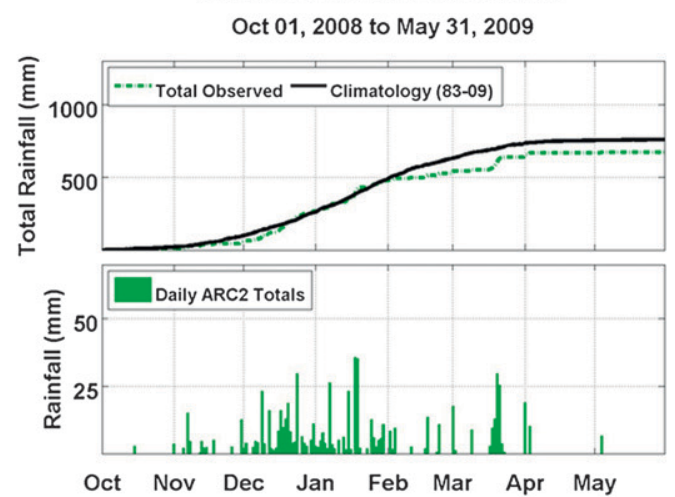

b.

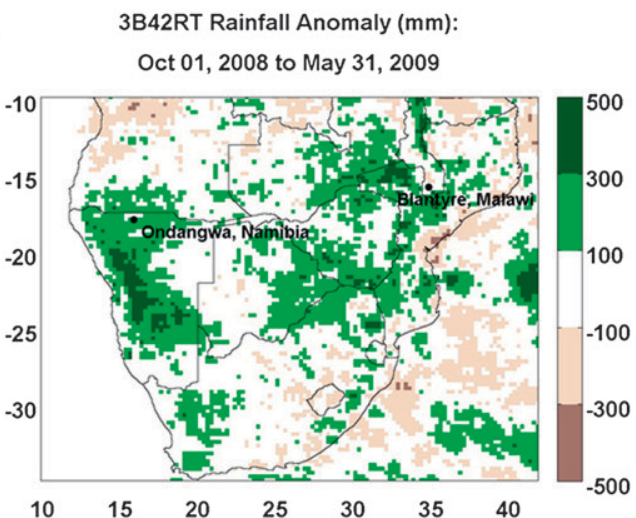

\section{d. \\ 3B42RT Rainfall at: Ondangwa, Namibia Oct 01, 2008 to May 31, 2009}

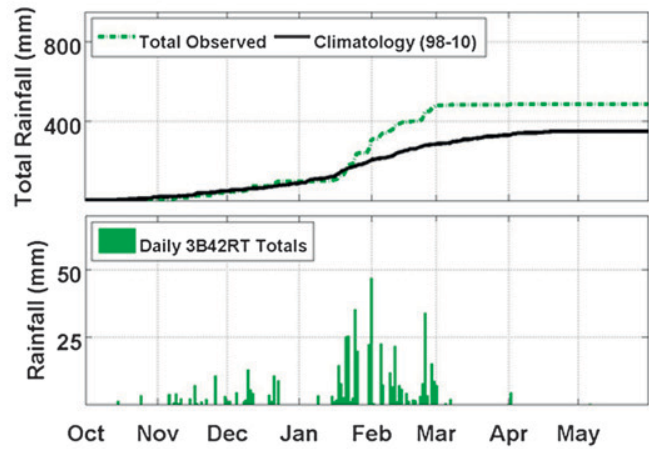

f. 3B42RT Rainfall at: Blantyre, Malawi Oct 01,2008 to May 31, 2009

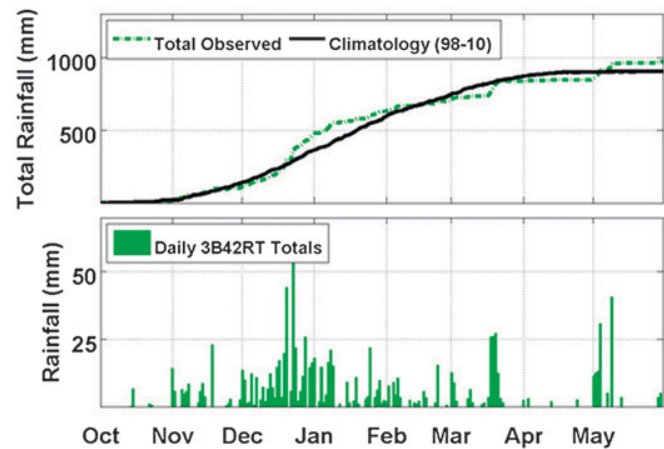

FIG. 11. Map of (a) ARC2 rainfall anomaly ( $\mathrm{mm})$, (b) 3B42RT total rainfall anomaly (mm), and observed and accumulative (c) ARC2, as well as (d) 3B42RT rainfall time series from Ondangwa, and (e) ARC2 and (f) 3B42RT rainfall time series of Blantyre, for the southern Africa rainy season (1 Oct 2008-31 May 2009).

West African Sahel (WAGA), it has been shown that ARC2 outperforms the 3B42v6 and CMORPH daily rainfall estimators. ARC2 yields the lowest amount of bias and RMSE (1 and 11.3), as the 3B42v6 and CMORPH products show a predominant tendency to overestimate rainfall in this region with bias scores of 1.06 and 1.46, respectively, and RMSE scores of 13.43 and 14.08, respectively. With GTS stations in the Sahel region reporting $80 \%$ more of the time than the Gulf of Guinea region, this also reinforces the point that the availability of gauge data may play a pivotal role in the ARC2's estimation performance. However, validation results over Ethiopia showed that ARC2 tends to underestimate more precipitation than the $3 \mathrm{~B} 42 \mathrm{v} 6$ and 

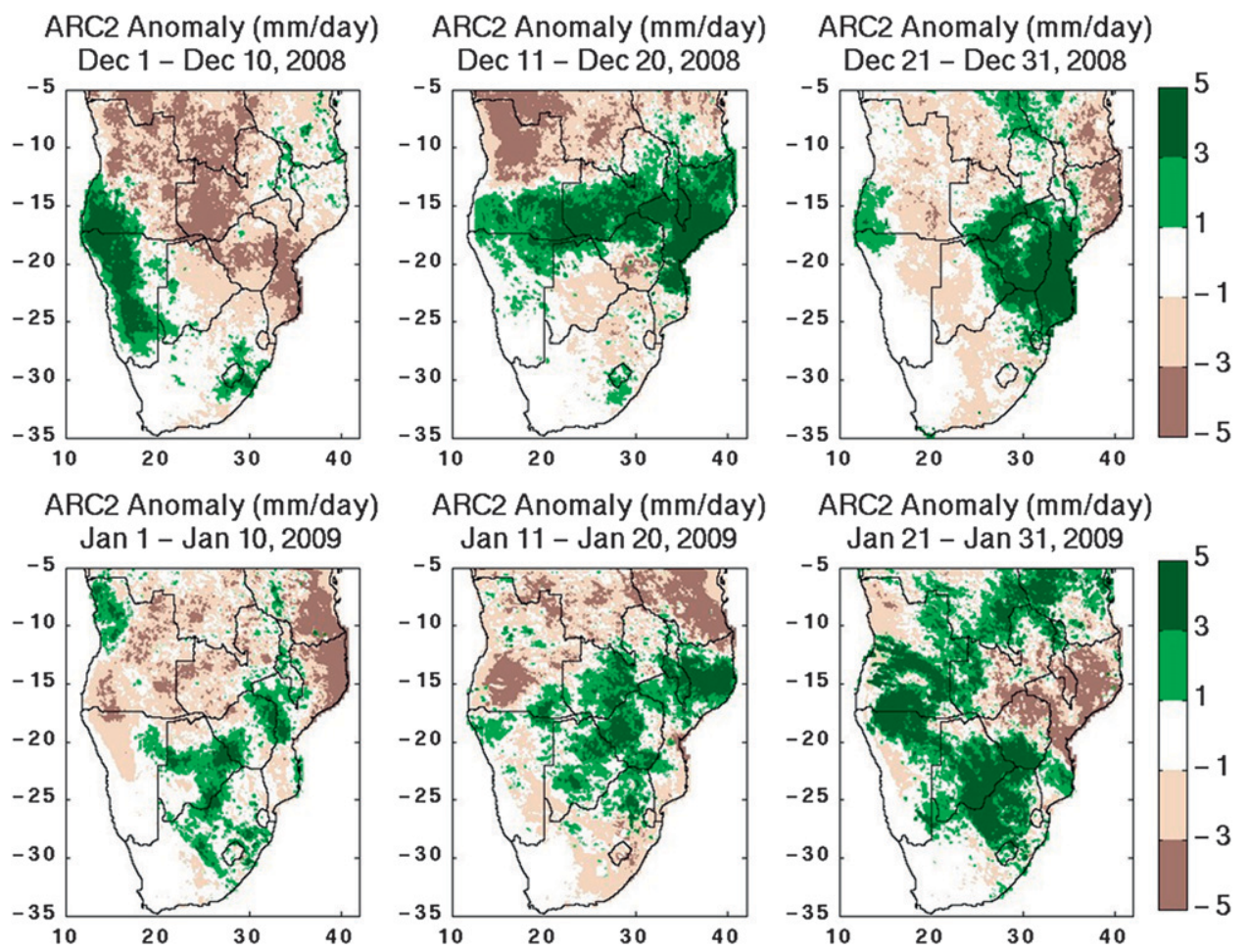

ARC2 Anomaly (mm/day)

Feb 1 - Feb 10, 2009

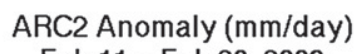

ARC2 Anomaly (mm/day)

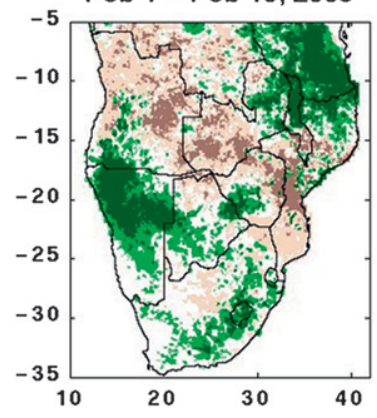

Feb 11 - Feb 20, 2009

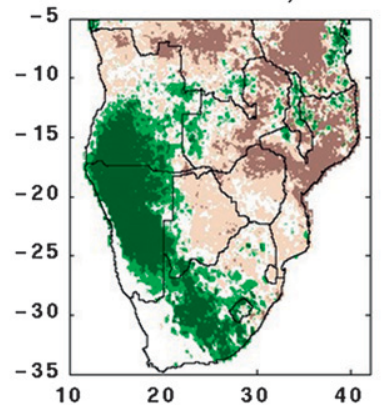

Feb 21 - Feb 28, 2009

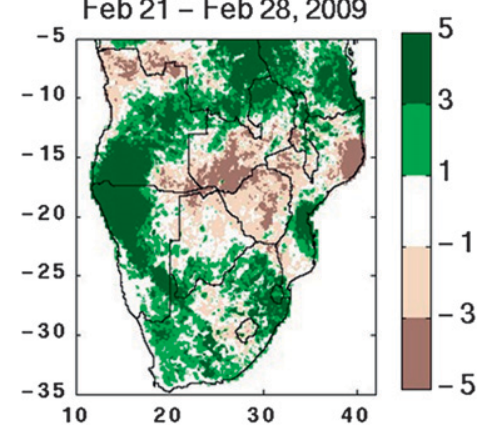

FIG. 12. Spatial analyses of dekadal ARC2 anomalies and their evolution from (top left) December 2008 to (bottom right) February 2009 over southern Africa.

CMORPH products with the highest bias and RMSE score of 0.55 and 10.65 , respectively. Bias and error scores were also higher when elevation was taken into consideration. Unlike ARC2, 3B42v6 uses microwave data to calibrate the IR estimates, while CMORPH does not use IR rainfall retrievals in its final rainfall estimates. Neither 3B42v6 nor CMORPH uses real-time gauge adjustments; this suggests that underestimations in ARC2 over Ethiopia are likely the result of the constant brightness temperature threshold used in the IR rainfall retrieval in the RFE-ARC2 algorithm (i.e., GPI). From these validations, we conclude that the observed summer dry biases are associated with the unavailability of GTS data and deficiencies in the IR-based estimates to capture warm-cloud precipitation over coastal and orographic areas. These findings have been reported previously in the literature (Dinku et al. 2007; Herman et al. 1997).

Despite these shortcomings, the value of ARC2 is in its availability in real time, which makes it convenient not only for climate studies but also for real-time climate monitoring. The fact that it is continuous, with a daily rainfall climatology at a high resolution, will help users better understand the finescale evolution and character of monsoonal precipitation over many remote regions of Africa. As evidenced in the case studies discussed in section 5, ARC2 can be used to diagnose wet and dry spells and capture extreme rainfall events, as well as the 
ARC2 Anomaly (mm/day)

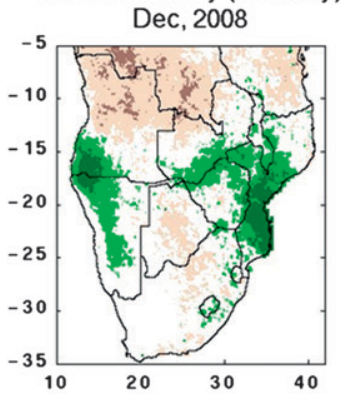

ARC2 Anomaly ( $\mathrm{mm} /$ day)

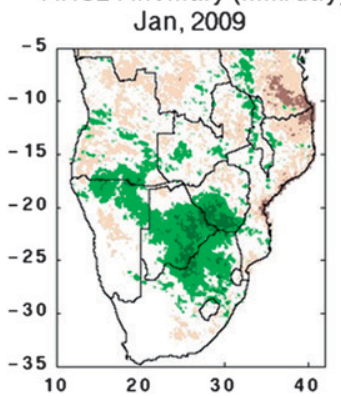

ARC2 Anomaly (mm/day)

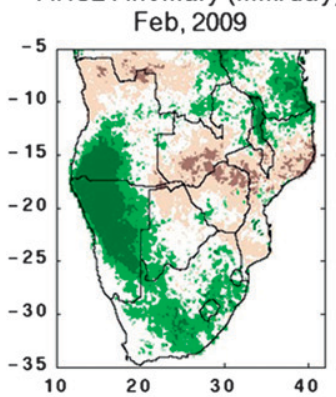

ARC2 Anomaly (mm/day)

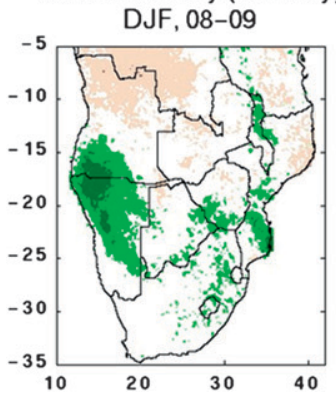

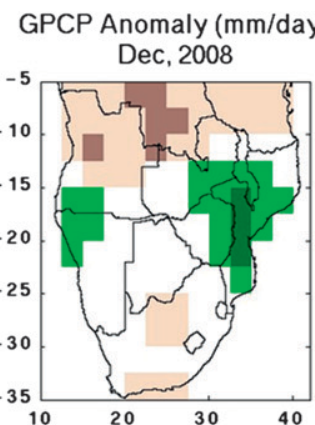

CMAP Anomaly (mm/day)

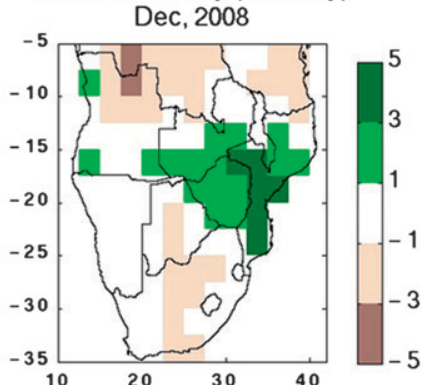

GPCP Anomaly (mm/day)

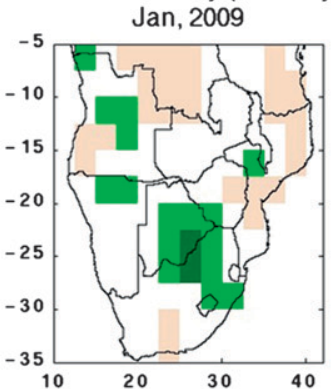

CMAP Anomaly (mm/day)

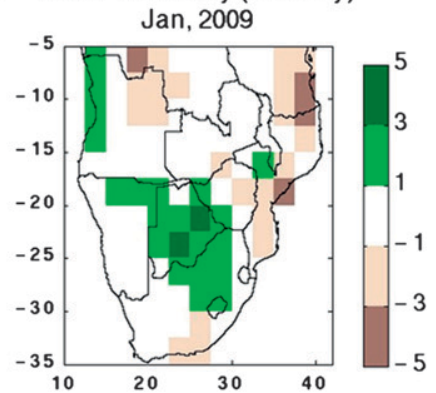

GPCP Anomaly (mm/day) Feb, 2009

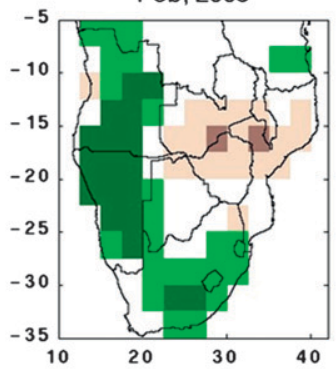

CMAP Anomaly (mm/day)

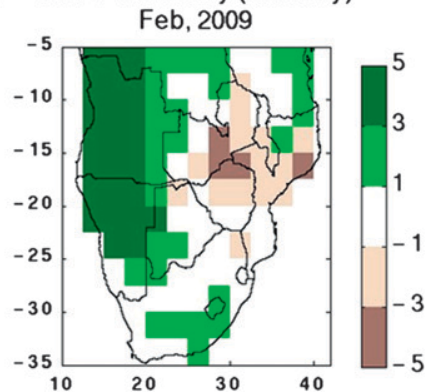

GPCP Anomaly ( $\mathrm{mm} /$ day)

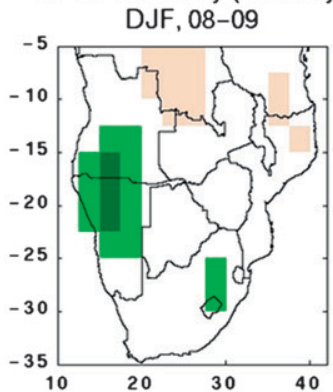

CMAP Anomaly ( $\mathrm{mm} /$ day)

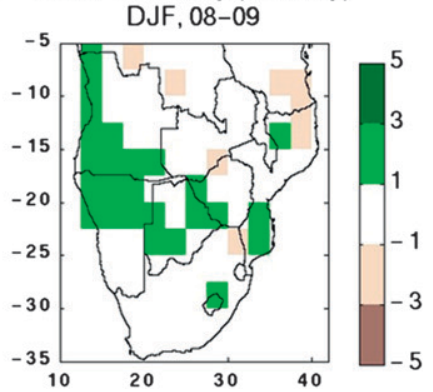

FIG. 13. Spatial analyses of (top three rows) monthly and (bottom row) seasonal (left) ARC2, (middle) GPCP, and (right) CMAP anomalies $\left(\mathrm{mm} \mathrm{day}^{-1}\right.$ ) from December 2008 to February 2009 over southern Africa.

onset, peak, and departure of seasonal precipitation across Africa. These attributes are important for improved decision-making parameters related to food security that monthly and other daily datasets cannot provide.
ARC2 is already being used in the assessment of the impacts of rainfall anomalies on agriculture in Africa. It will continue to be a valuable tool for water requirement analyses for local-scale crops, drought monitoring, and other various socioeconomic indices. The extended 
record of the new ARC climatology provides nearly $30 \mathrm{yr}$ of daily precipitation estimates. Using consistent and reliable data as inputs for the ARC2 is essential to the continuity and homogeneity of this long-term record. The simplicity of this process minimizes the possibility of introducing errors and/or other biases associated with new rainfall inputs moving forward. ARC2 will be of particular relevance and importance within the context of understanding climate variability and change.

Acknowledgments. This work was supported with funds from USAID/Famine Early Warning System Network and partial funds from the World Food Program.

\section{REFERENCES}

Adler, R. F., and Coauthors, 2003: The version-2 Global Precipitation Climatology Project (GPCP) monthly precipitation analysis (1979-present). J. Hydrometeor., 4, 1147-1167.

Arkin, P. A., and B. N. Meisner, 1987: The relationship between large-scale convective rainfall and cold cloud over the Western Hemisphere during 1982-84. Mon. Wea. Rev., 115, 51-74.

- and P. Xie, 1994: The Global Precipitation Climatology Project: First Algorithm Intercomparison Project. Bull. Amer. Meteor. Soc., 75, 401-419.

Chen, M., P. Xie, J. Janowiak, and P. A. Arkin, 2002: Global land precipitation: A 50-yr analysis based on gauge observations. J. Hydrometeor., 3, 249-266.

Dinku, T., P. Ceccato, E. Grover-Kopec, M. Lemma, S. J. Connor, and C. F. Ropelewski, 2007: Validation of satellite rainfall products over East Africa's complex topography. Int. J. Remote Sens., 28, 1503-1526.

EUMETSAT, cited 2011a: Meteosat first generation calibration coefficients and conversion methods. [Available online at http://www.eumetsat.int/Home/Main/DataProducts/Calibration/ MFGCalibration/index.htm?l=en.]

— OPS/USR/10/1537, version V1A, Meteorological Archive and Retrieval Facility, Darmstadt, Germany, 40 pp. [Available online at http://www.eumetsat.int/groups/ops/documents/ document/pdf_td06_marf.pdf.]

Ferraro, R. R., and G. F. Marks, 1995: The development of SSM/I rain-rate retrieval algorithms using ground-based radar measurements. J. Atmos. Oceanic Technol., 12, 775-780.

— N. N. Crody, F. Weng, and A. Basist, 1996: An eight-year (1987-1994) time series of rainfall, clouds, water vapor, snow cover, and sea ice derived from SSM/I measurements. Bull. Amer. Meteor. Soc., 77, 891-906.

Herman, A., V. Kumar, P. A. Arkin, and J. V. Kousky, 1997: Objectively determined 10-day African rainfall estimates created for famine early warning. Int. J. Remote Sens., 18, 2147-2159.

Huffman, G. J., and D. T. Bolvin, 2009: GPCP version 2.1 combined precipitation data set documentation. NASA Goddard Space Flight Center Laboratory for Atmospheres and Science Systems and Applications, Inc.
— - and Coauthors, 1997: The Global Precipitation Climatology Project (GPCP) combined precipitation dataset. Bull. Amer. Meteor. Soc., 78, 5-20.

— and Coauthors, 2007: The TRMM Mulisatellite Precipitation Analysis (TMPA): Quasi-global, multiyear, combined-sensor precipitation estimates at fine scales. J. Hydrometeor., 8 , $38-55$.

— R. F. Adler, D. T. Bolvin, and E. Nelkin, 2010: The TRMM Multi-Satellite Precipitation Analysis. Satellite Rainfall Applications for Surface Hydrology, F. Hossian and M. Gebremichael, Eds., Springer, 3-22.

Jobard, I., F. Chopin, J. C. Berges, and R. Roca, 2011: An intercomparison of 10-day satellite precipitation products during West African monsoon. Int. J. Remote Sens., 32, 2353-2376.

Joyce, R., and P. A. Arkin, 1997: Improving estimates of tropical and subtropical precipitation using the GOES precipitation index. J. Atmos. Oceanic Technol., 14, 997-1011.

—, J. Janowiak, P. A. Arkin, and P. Xie, 2004: CMORPH: A method that produces global precipitation estimates from passive microwave and infrared data at high spatial and temporal resolution. J. Hydrometeor., 5, 487-503.

Love, T. B., V. Kumar, P. Xie, and W. Thiaw, 2004: A 20-year daily Africa precipitation climatology using satellite and gauge data. Preprints, 14th Conf. on Applied Meteorology, Seattle, WA, Amer. Meteor. Soc., P5.4. [Available online at http:// ams.confex.com/ams/pdfpapers/67484.pdf.]

Reynolds, R. W., 1988: A real-time global sea surface temperature analysis. J. Climate, 1, 75-86.

Rudolf, B., W. Hauschild, W. Rueth, and U. Schneider, 1994: Terrestrial precipitation analysis: Operational method and required density of point measurements. Global Precipitations and Climate Change, M. Desbois and F. Désalmand, Eds., NATO ASI Series, Vol. 26, 173-186.

Semunegus, H., W. Berg, J. Bates, K. Knapp, and C. Kummerow, 2010: An extended and improved Special Sensor Microwave Imager (SSM/I) period of record. J. Appl. Meteor. Climatol., 49, 424-436.

Shepard, D., 1968: A two-dimensional interpolation function for irregularly spaced data. Proc. 23rd National Conf. of American Computing Machinery, Princeton, NJ, Assoc. Computing Machinery, 517-524.

Vila, D., R. Ferraro, and R. Joyce, 2007: Evaluation and improvement of AMSU precipitation retrievals. J. Geophys. Res., 112, D20119, doi:10.1029/2007JD008617.

Xie, P., and P. A. Arkin, 1995: An intercomparison of gauge observations and satellite estimates of monthly precipitation J. Appl. Meteor., 34, 1143-1160.

$\ldots$, and — 1996: Analyses of global monthly precipitation using gauge observations, satellite estimates, and numerical model predictions. J. Climate, 9, 840-858.

— analysis based on gauge observations, satellite estimates, and numerical model outputs. Bull. Amer. Meteor. Soc., 78, 2537 2558.

Zhao, L., R. Ferraro, and D. Moore, 2000: Validation of NOAA-15 AMSU-A rain rate algorithms. Preprints, 10th Conf. on Satellite Meteorology and Oceanography, Long Beach, CA, Amer. Meteor. Soc., 192-195. 